\title{
Statins as Regulators of Redox State in the Vascular Endothelium: Beyond Lipid Lowering
}

\author{
Marios Margaritis, Keith M. Channon, and Charalambos Antoniades
}

\begin{abstract}
Significance: Endothelial dysfunction and the imbalance between nitric oxide (NO) and reactive oxygen species production in the vascular endothelium are important early steps in atherogenesis, a major socioeconomic health problem. Statins have well-established roles in primary and secondary prevention of cardiovascular disease (CVD), due to both their lipid-lowering capacity and their pleiotropic properties. It is therefore important to understand the mechanisms by which statins can modify endothelial function and affect atherogenesis. Recent Advances: In the last decade, the concept of statin pleiotropy has been reinforced by a large number of cell culture, animal, and translational studies. Statins have been shown to suppress the activity of pro-oxidant enzymes (such as NADPH oxidase) and pro-inflammatory transcriptional pathways in the endothelium. At the same time, they enhance endothelial NO synthase expression and activity while they also improve its enzymatic coupling. This leads to increased NO bioavailability and improved endothelial function. Critical Issues: Despite significant recent advances, the exact mechanisms of statin pleitropy are still only partially understood. The vast majority of the published literature relies on animal studies, while the actual mechanistic studies in humans are limited. Future Directions: The success of statins as endothelium redox-modifying agents with a direct impact on clinical outcome highlights the importance of the endothelium as a therapeutic target in CVD. Better understanding of the mechanisms that underlie endothelial dysfunction could lead to the design of novel therapeutic strategies that target the vascular endothelium for the prevention and treatment of CVD. Antioxid. Redox Signal. 20, 1198-1215.
\end{abstract}

\section{Introduction}

TN THE MODERN ERA, cardiovascular medicine is largely focused on primary and secondary prevention of cardiovascular diseases (CVDs), and hypolipidemic agents like statins are in the forefront of this effort. During the last decade, large-scale randomized clinical trials have confirmed the role of statins on cardiovascular risk reduction in both primary and secondary prevention: (i) they reduce nonfatal events in patients at risk of or with CVD (67), (ii) they lower the incidence of post-procedural myocardial infarction (120), (iii) they improve clinical outcome after stroke (75), and (iv) they even reduce the incidence of major vascular events in low-risk individuals in the context of primary prevention (66). Moreover, intensive over-moderate statin therapy has been shown to reduce all-cause mortality in patients presenting with acute coronary syndrome (ACS) (19), as well as nonfatal events in stable and acute coronary patients (3).

It is widely recognized that endothelial dysfunction in the human arterial wall is a major early step in atherogenesis and it is characterized by reduced production of the vasodilator nitric oxide (NO). Exposure of the endothelium to reactive oxygen species (ROS) plays a major role in the pathophysiology of endothelial dysfunction. Dysregulation of vascular homeostasis due to reduced NO bioavailability triggers a cascade of events that ultimately lead to the formation of the atherosclerotic plaque (9). Therefore, evidence suggests that interventions aiming at improving the balance between ROS and NO bioavailability in the vascular endothelium may be beneficial in both primary and secondary prevention. 


\section{The Role of Vascular Endothelium in Atherosclerosis}

Endothelial dysfunction is widely regarded as one of the key early events in the atherosclerotic process. Endothelial dysfunction is characterized by reduced availability of NO; this is a gaseous molecule that diffuses to the vascular smooth muscle cells (VSMCs), triggers an increase in intracellular cyclic GMP, and induces vasorelaxation. Therefore, it has a major role in the regulation of vascular tone, as it opposes the actions of vasoconstricting factors such as endothelin-1. Moreover, NO is also implicated in the regulation of other processes, such as platelet aggregation and leukocyte adhesion, thus playing an integral role in vascular homeostasis (28).

The major enzymatic source of $\mathrm{NO}$ in the vasculature is endothelial nitric oxide synthase (eNOS), which is located predominantly in endothelial cells (ECs). eNOS is a complex homodimer that uses L-arginine and molecular oxygen $\left(\mathrm{O}_{2}\right)$ as substrate to produce NO and L-citrulline (Fig. 1). This is achieved through the transfer of electrons, using NADPH as a donor, from the flavins of the reductase domain on one monodimer to the oxidase domain of the other, where the iron-containing heme active site is located (22). The presence of calmodulin, which is activated by calcium binding, increases the rate of electron flow. At the heme site, the electrons are utilized to reduce and activate $\mathrm{O}_{2}$, which is in turn used to produce $\mathrm{NO}$ through a two-step oxidation of L-arginine. This process requires the binding of the essential cofactor tetrahydrobiopterin $\left(\mathrm{BH}_{4}\right)$; the rate-limiting enzyme in the $\mathrm{BH}_{4}$ biosynthesis pathway is guanosine triphosphate cyclohydrolase (GTPCH). When $\mathrm{BH}_{4}$ is bound to eNOS, the enzyme is considered to be "coupled" (55). Coupling of eNOS is essential for the physiological function of the human vessel. Degradation of $\mathrm{BH}_{4}$ by $\mathrm{ROS}$, especially peroxynitrite $\left(\mathrm{ONOO}^{-}\right)$, leads to what is known as "uncoupling" of the enzyme. In the absence of $\mathrm{BH}_{4}$, the flow of electrons within eNOS is disturbed; this leads to dissociation of the ferrous-dioxygen complex, causing eNOS to convert $\mathrm{O}_{2}$ into superoxide $\left(\mathrm{O}_{2}{ }^{-}\right)$ radicals instead of producing $\mathrm{NO}(4) . \mathrm{O}_{2}{ }^{-}$reacts with $\mathrm{NO}$ to form $\mathrm{ONOO}^{-}$, which can further oxidize $\mathrm{BH}_{4}$, creating a vicious cycle of eNOS uncoupling. The resulting drop in production of $\mathrm{NO}$ inhibits endothelium-dependent vasorelaxation, disturbs vascular homeostasis, and leads to endothelial dysfunction (55). In addition, $\mathrm{ONOO}^{-}$has well-established roles in low-density lipoprotein (LDL) oxidation and is also responsible for the nitration of various cellular components; accumulation of nitrated proteins is a potent marker of oxidative/nitrosative cellular damage. $\mathrm{ONOO}^{-}$ can induce cellular apoptosis and even necrosis at high concentrations, further aggravating endothelial dysfunction (81).

Another mechanism by which eNOS function is negatively affected is through the effects of the endogenous eNOS inhibitor asymmetric dimethylarginine (ADMA). ADMA is produced as a by-product of protein metabolism through methylation of L-arginine residues, and its production is greatly increased by LDL in ECs (15). ADMA is metabolized by the enzyme dimethylarginine dimethylaminohydrolase

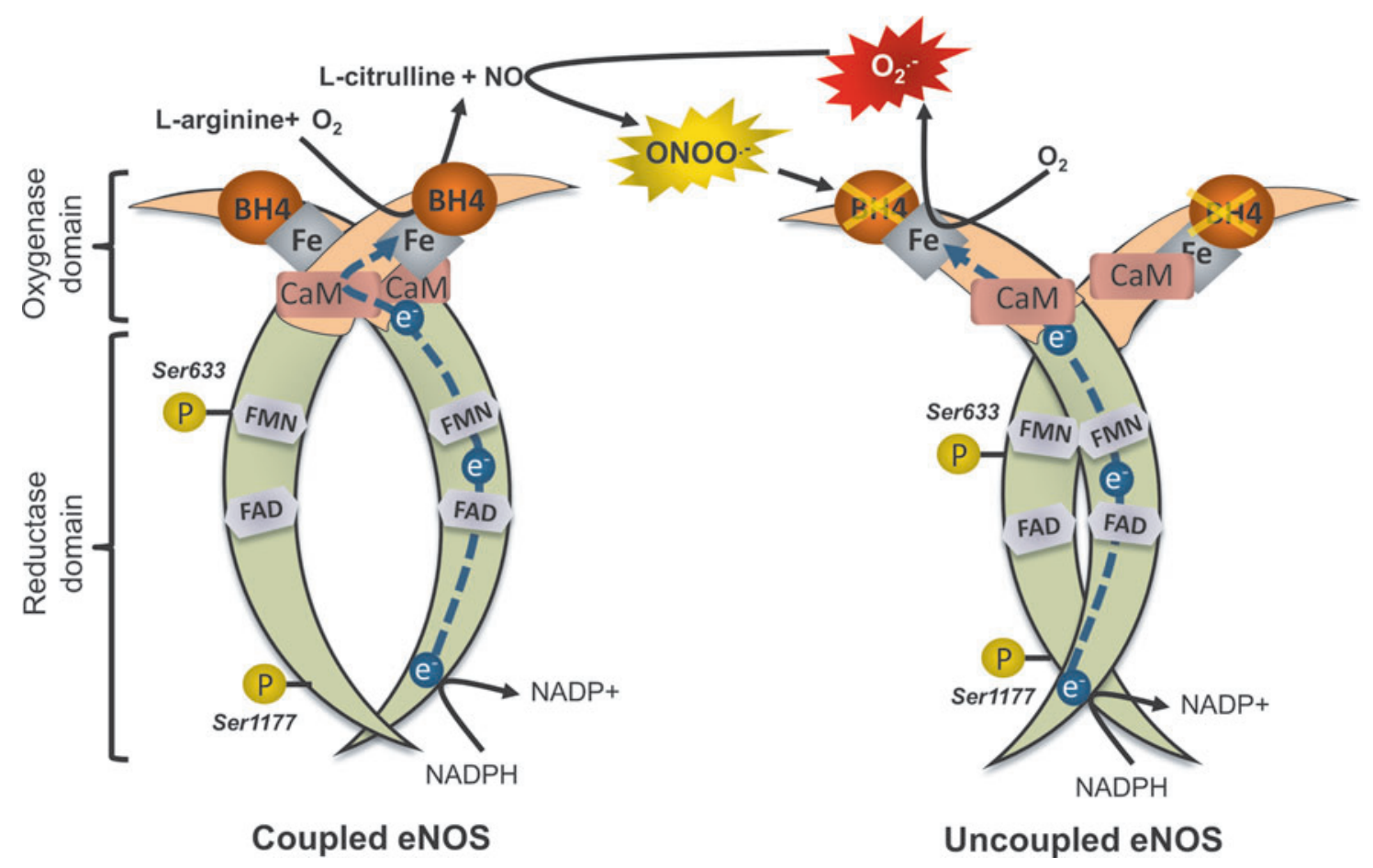

FIG. 1. Uncoupling of eNOS. In the presence of $\mathrm{BH}_{4}$, eNOS shuttles electrons from the flavins of the reductase domain of one monodimer to the oxygenase domain of the other monodimer, in a two-step reaction that produces L-citrulline and NO from L-arginine and $\mathrm{O}_{2} \cdot \mathrm{BH}_{4}$ is sensitive to degradation by $\mathrm{ROS}$, especially $\mathrm{ONOO}^{-}$. In the absence of $\mathrm{BH}_{4}$, eNOS is uncoupled; electrons are transferred to $\mathrm{O}_{2}$, producing $\mathrm{O}_{2}{ }^{-} \cdot \mathrm{O}_{2}{ }^{-}$reacts rapidly with $\mathrm{NO}$ to form $\mathrm{ONOO}^{-}$, which can further oxidize $\mathrm{BH}_{4}$, creating a vicious circle that leads to endothelial dysfunction. Ser-1177 and Ser-633 are activation phosphorylation sites, which are hypothetical targets of statins. eNOS, endothelial nitric oxide synthase; $\mathrm{BH}_{4}$, tetrahydrobiopterin; $\mathrm{O}_{2}{ }^{-}$, superoxide; $\mathrm{ONOO}^{-}$, peroxynitrite; ROS, reactive oxygen species; $\mathrm{NO}$, nitric oxide. To see this illustration in color, the reader is referred to the web version of this article at www.liebertpub.com/ars 
(DDAH) and eliminated through urinary excretion (108). Due to its close resemblance in structure to L-arginine, ADMA inhibits activity of eNOS, either through inhibition of cellular L-arginine uptake or direct competitive inhibition for binding to eNOS (8). In vitro experiments using purified neuronal NOS suggest that ADMA acts mainly by inhibiting the enzyme rather than inducing its uncoupling (20). However, it was suggested that ADMA induces eNOS uncoupling in the presence of partial $\mathrm{BH}_{4}$ deficiency (20), which is a common condition in the human vascular endothelium in advanced disease states. In line to this observation, exposure of EC cultures to ADMA increases ROS generation (15) and accelerates cell senescence (96), possibly through an induction of eNOS uncoupling in vivo. High levels of ADMA have been associated with impaired endothelial function and increased ROS generation in the human vasculature (8), while in prospective studies, circulating ADMA is independently related to increased mortality and worse clinical outcome in patients with atherosclerosis or diabetes (14).

Measurement of endothelial function has been established as an important predictor of future cardiovascular events, independent of other risk factors. A number of studies have demonstrated an association between impaired flowmediated dilatation (FMD) of the brachial artery (a noninvasive, ultrasound-based method for determining endothelial function) and increased risk of cardiovascular events in patients undergoing vascular surgery (38), as well as in the absence of obstructive atherosclerotic disease (104). A very recent meta-analysis concluded that FMD of the brachial artery is inversely associated with risk of CVD events, possibly more so in populations already at higher risk based on traditional predisposing factors, suggesting that $1 \%$ increase in FMD leads to reduction of cardiovascular risk by $9 \%$ (90).

\section{Oxidative Stress in Atherosclerosis}

Our current understanding of CVD pathogenesis supports a major role for ROS in atherogenesis (10). Classic atherosclerotic risk factors, such as diabetes mellitus, hypertension, and smoking, have all been linked to elevated production of ROS by the vascular wall (10). A major event in the atherosclerotic process is oxidation of lipoprotein molecules, primarily LDL by ROS, leading to the formation of oxidized LDL (oxLDL). This takes place primarily in the subendothelial space rather than in plasma, which hosts a variety of antioxidant defense mechanisms (37). ROS-mediated uncoupling of eNOS causes dysfunction of the endothelial layer, through the mechanisms presented previously. Binding of oxLDL to the lectin-like oxidized receptor triggers activation of redoxsensitive, proinflammatory transcriptional pathways (such as nuclear factor kappa B [NF- $\kappa \mathrm{B}]$ ) in ECs. This induces the release of inflammatory cytokines (such as interleukin [IL]-6) and increases the expression of cellular adhesion molecules (such as vascular cellular adhesion molecule 1 [VCAM-1]). As a result, circulating monocytes are attracted to the vascular endothelium, where they adhere due to increased expression of adhesion molecules and infiltrate the subendothelial space. There, they phagocyte oxLDL molecules, acquire macrophage-like characteristics, and eventually transform into foam cells. This further aggravates the inflammatory processes triggered in the vascular wall and creates a vicious circle where more monocytes/macrophages are attracted to the subendothelial space. In addition, ROS and inflammatory cytokines trigger VSMC migration from the media to the intima. The accumulation of lipid-laden foam cells and the parallel migration/proliferation of VSMCs eventually lead to atherosclerotic plaque formation.

Although the presence of increased oxidative stress in atherosclerosis cannot be doubted, actual causality has not been conclusively proven in humans. Several questions have been raised on whether increased ROS generation constitutes an actual cause of atherosclerosis or if it is simply a consequence or a bystander in the process (60). Mechanistic studies in humans are always challenging, given that access to human tissue is limited; therefore, proving a causal relationship is difficult. The oxidative stress hypothesis has been extensively explored in experimental models, and clinical studies have yielded results that are largely consistent with basic studies. Therefore, oxidative stress is now widely accepted as a key component of human CVD (17).

Given the implication of ROS in the pathogenesis of atherosclerosis, a logical therapeutic approach seemed at first to be the administration of dietary antioxidant supplements, such as ascorbic acid (vitamin C), $\alpha$-tocopherol (vitamin E), and others. These compounds act as exogenous ROS scavengers and their supplementation was considered to be a rational therapeutic attempt at restoring vascular redox balance and preventing CVD. Indeed, since 1994, more than 50 large randomized trials that used antioxidant vitamins in primary and secondary CVD prevention have been published, with disappointing results. The latest meta-analysis, based on a total population of almost 300,000 participants spread across 50 randomized trials, concludes that there is no evidence in favor of antioxidant supplementation to prevent CVD (73).

The disappointing results of the antioxidant supplement trials should not in any case be interpreted as an invalidation of the oxidative stress hypothesis. For example, Patrignani et al. (82) found that supplementation with pharmacological doses of vitamin E up to $1200 \mathrm{mg} /$ day was not associated with any detectable change in urinary 8-iso-PGF2a excretion (a noninvasive marker of oxidant stress in vivo) in healthy cigarette smokers. In contrast, comparable pharmacological doses of vitamin E affect 8-iso-PGF2a in clinical settings of patients with CVD risk factors and inflammation. Interestingly, they showed that there is a linear correlation between the basal rate of 8-iso-PGF2a excretion and the slope of changes in this index of lipid peroxidation as a function of changes in plasma vitamin E associated with short-term dosing with $600 \mathrm{mg} /$ day in different clinical settings. These results are consistent with the hypothesis that the basal rate of lipid peroxidation is a major determinant of the response to vitamin E supplementation.

Aside from methodological issues concerning the design, population, and dosage of antioxidants in the clinical trials, there could also be biological reasons behind the failure of traditional, dietary antioxidant-based strategies to exert any beneficial effect on CVD prevention. All of the compounds tested in trials act as scavengers of ROS in vivo; they do not prevent the formation of ROS by cellular enzymatic systems, but rather eliminate ROS already formed in an attempt to restore redox balance. However, compartmentalization of ROS formation is an important aspect of redox physiology; a large number of enzymatic systems generate intracellular ROS, in distinct cellular compartments or organelles, such as 
the mitochondria (34). In addition, ROS are not just harmful by-products of cellular metabolism; they are important signaling molecules involved in a plethora of signaling transduction cascades that mediate responses to stress, injury, hypoxia, and so on (64). Indiscriminate, nontargeted scavenging of ROS, as achieved through most antioxidant strategies tested in clinical trials, would not necessarily restore redox balance, due to the inability of these compounds to reach the proper cellular compartment, but also through interference with potentially beneficial ROS-mediated signaling pathways.

Therefore, an effective antioxidant compound should not act as a simple ROS scavenger, but rather it should achieve a targeted inhibition of increased ROS generation by dysregulated ROS-generating enzymatic systems, while at the same time maintaining the beneficial effects of low-level ROSmediated signaling. For example, Dikalova et al. (34) showed that a mitochondria-targeted $\mathrm{O}_{2}{ }^{-}$scavenger managed to significantly attenuate angiotensin II-induced hypertension and total $\mathrm{O}_{2}{ }^{-}$production in an animal model, whereas a nontargeted scavenger did not. Similarly, statins, both through their LDL-lowering actions and through their pleiotropic effects on ROS-generating enzymatic systems in the vascular wall, could constitute an elegant and efficient strategy aimed at restoring redox balance compared to traditional antioxidant supplements.

\section{The Role of Statins in Cardiovascular Medicine: An Effective Lipid-Lowering Strategy}

Statins are organic molecules originally derived from fungi. They exert their effects by inhibiting the enzyme 3-hydroxy-3methylglutaryl coenzyme A (HMG-CoA) reductase, by competitively inhibiting binding of substrate to the active site of the enzyme, owing to their similarity in structure to HMGCoA (47). HMG-CoA reductase is the rate-limiting enzyme in the mevalonate pathway (Fig. 2). This enzyme converts HMGCoA into mevalonate, which is subsequently phosphorylated and converted into isopentenyl pyrophosphate (IPP) and dimethylallyl pyrophosphate (DMAPP). These molecules serve as precursors to the isoprenoid farnesylpyrophosphate (FPP), which is converted into geranyl-geranyl-pyrophosphate (GGPP) and squalene. In hepatic cells, squalene forms the basis of ergosterol and subsequently cholesterol synthesis. Because a significant percentage of the total cholesterol in the human body is endogenously produced (rather than up-taken by diet), inhibition of HMG-CoA by statins leads to a subsequent reduction in cholesterol and particularly low-density lipoprotein (LDL) biosynthesis (63).

Many large-scale randomized clinical trials have shown that lipid-lowering strategies that include statins have an antiatherogenic potential and suppress the risk of myocardial infarction and stroke. The landmark WOSCOPS trial (West of Scotland Coronary Prevention Study Group) demonstrates a $31 \%$ reduction in coronary events in patients with hypercholesterolemia after treatment with pravastatin ( $40 \mathrm{mg} /$ day) (98). Since then, a number of studies have provided more evidence of beneficial effects for primary prevention; the latest Cochrane Database review concludes that statins reduce vascular events and all-cause mortality in subjects without evidence of prior CVD (106). Similarly, the Long-Term Intervention with Pravastatin in Ischaemic Disease (LIPID) trial

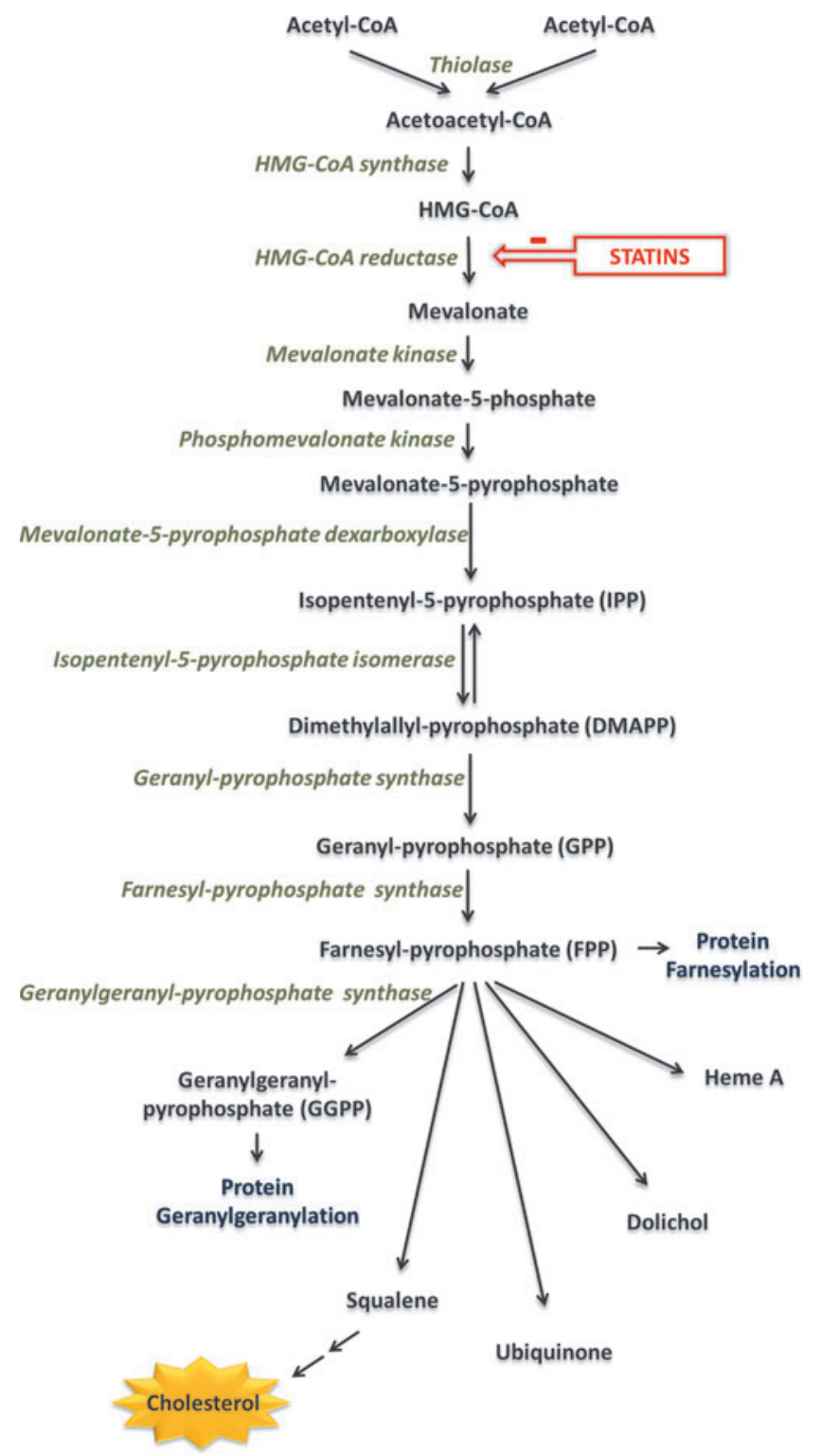

FIG. 2. The mevalonate pathway. Statins inhibit HMGCoA reductase, the rate-limiting enzyme in the mevalonate pathway. Through subsequent phosphorylations, mevalonate is converted to IPP and DMAPP, which are used to produce FPP. FPP serves as precursor molecule to a variety of bioactive compounds, such as heme, dolichol, ubiquinone, and squalene, itself a precursor of cholesterol in hepatic cells. FPP can also be converted to GGPP, which is used by cells for geranylgeranylation of proteins, such as Rho and Rac. HMG-CoA, 3-hydroxy-3-methylglutaryl coenzyme A; DMAPP, dimethylallyl pyrophosphate; FPP, farnesylpyrophosphate; GGPP, geranyl-geranyl-pyrophosphate; IPP, isopentenyl pyrophosphate. To see this illustration in color, the reader is referred to the web version of this article at www.liebertpub.com/ars

demonstrates significantly reduced coronary and all-cause mortality in patients who received pravastatin $(40 \mathrm{mg} /$ day) versus placebo following an ACS (2). In addition, the Post Coronary Artery Bypass Graft (POST-CABG) trial shows a reduction of saphenous vein graft (SVG) obstructive atherosclerotic disease in patients under aggressive lipid-lowering 
treatment with lovastatin \pm cholestyramine compared to more conservative treatment (1). As a result of these and other large-scale trials, statins now form an integral part of the medicinal regimen prescribed following a major cardiovascular event; the latest AHA/ACCF guidelines recommend initiation of statin therapy as secondary prevention in the presence of coronary or other atherosclerotic vascular disease (class IA), with target LDL levels below $100 \mathrm{mg} / \mathrm{dl}$ aiming for at least a $30 \%$ reduction from previous levels (101).

\section{Pleiotropic Effects of Statins: Beyond Lipid Lowering}

Most of the early clinical trials focused on dyslipidemic individuals or CVD patients with high LDL cholesterol levels. However, analysis of the LIPID trial uncovers a beneficial effect of statin treatment in CVD patients against new-onset coronary events or need for revascularization, irrespective of their LDL levels (95). Similarly, post hoc analysis of the POSTCABG trial reveals a beneficial effect of intensive statin treatment on SVG disease independently of lipid lowering (35). The concept that statins could potentially have effects beyond their lipid-lowering capabilities is further reinforced by the landmark JUPITER trial, in which normolipemic, apparently healthy subjects with high $\mathrm{C}$-reactive protein (CRP) levels were randomized to rosuvastatin $20 \mathrm{mg}$ / day or placebo (92). The results of this study show that statin treatment reduces CRP levels and the incidence of major cardiovascular events. Statin effects that are independent of LDL lowering have been termed "pleiotropic" and have been the focus of extensive research in the past decade.

The concept of direct pleiotropic effects of statins on vascular endothelial function in humans has also been demonstrated by comparing the effects of different lipid-lowering strategies. In a randomized trial of chronic heart failure patients treated for 4 weeks with simvastatin or ezetimibe (10 mg/day), the statin arm shows markedly improved FMD of the brachial artery compared with the ezetimibe arm, despite the similar reduction of LDL levels in the two study groups (54). Similarly, in dyslipidemic patients without CVD, $40 \mathrm{mg}$ /day simvastatin treatment improves FMD and reduces vascular Rho kinase activity significantly more than simvastatin $10 \mathrm{mg}$ /day plus ezetimibe $10 \mathrm{mg}$ /day (58). Another recent meta-analysis that examines the effects of statin treatment on FMD in diabetic patients concludes that statins confer improvement of endothelial function, but only in patients who did not already present with severe endothelial dysfunction (125); this highlights the role of early prevention and modification of risk factors, in addition to the beneficial effects of statin treatment. Interestingly, sudden discontinuation of simvastatin treatment in patients with coronary artery disease leads to significant reduction in FMD 1 week after halting treatment, an effect not correlated with rebound increase in LDL levels (58). Conversely, in healthy individuals, abrupt halting of statin treatment also leads to a decline in FMD in day 1 after discontinuation, which is restored to baseline levels in 1 week (58). These results highlight both the potency of the endothelium-protecting pleiotropic effects of statins, and the need for proper adherence to treatment.

As mentioned before, the isoprenoids FPP and GGPP are intermediate products of the mevalonate pathway, which is inhibited by statins. Protein prenylation (the addition of isoprene units) is an important post-translational modification.
The family of small GTP-ases (Ras, Rho, Rac, etc.) is an important cellular target for prenylation. Addition of FPP or GGPP moieties in proteins (farnesylation or geranylgeranylation) is critical for lipid anchoring and activation of Rho and Rac (11). Geranylgeranylation of Rho activates the Rho-associated protein kinase (ROCK); the Rho/ROCK pathway is implicated in the control of a variety of cellular functions, including proliferation, cell migration, redox signaling, and apoptosis (102). In addition, Rac is involved in the activation of the NADPHoxidase complex and thus plays a major role in regulation of ROS generation, as will be extensively discussed later on.

The mevalonate pathway is active not only in hepatocytes, where it was first described, but it is also important for cellular homeostasis of vascular cells (ECs and VSMCs). Lipophilic statins (such as atorvastatin and simvastatin) can be passively diffused through the lipid bilayer of the cellular membrane and can therefore be uptaken by a large number of cells and not just hepatocytes (which also possess mechanisms of active transport) (50) (Fig. 3). Direct inhibition of small GTP-ase prenylation in vascular cells forms the core of the hypothesis that explains the rapid pleiotropic effects of statins on the vascular wall, which are independent of lipid lowering.

\section{Sources of ROS as Therapeutic Targets in the Vascular Wall: Effects of Statins}

Cellular redox imbalance, characterized by increased production and reduced elimination of ROS, is implicated in many human pathophysiological disease states, including CVD. Statins are probably the most effective, currently available strategy that inhibit the pro-oxidant enzymatic systems present in the vasculature and enhance the antioxidant defense mechanisms.

The effects of statins on redox state regulation of ECs have been extensively explored in cell culture and animal models. However, results obtained from experiments performed in such "model systems" do not necessarily reflect human physiology and may not be applicable to human disease. For example, primary cells and even more so cell lines cannot in any way take into account the complex interactions that occur on a tissue level. In addition, a large number of experiments have been performed in human umbilical vein endothelial cells (HUVECs), which exhibit significant functional differences compared with arterial ECs, which are more relevant to the development of atherosclerosis. Moreover, some cell culture studies have used concentrations of statins that are many folds higher than what is thought to be achievable in vivo. Similarly, even though this issue does not exist with animal models that have been treated with statins, there are significant differences in the pathophysiology of atherosclerosis compared with humans, which makes interpretation of the results challenging. However, in the literature, there are a large number of human translational studies, which have yielded similar results with the findings of cell and animal models. The remarkable consistency of the translational study results reinforces the validity of the original findings from basic science studies on the effects of statins on the regulation of redox state in ECs.

\section{Effects of statins on eNOS}

It is well documented in the literature that the pleiotropic effects of statins in the vasculature are at least partly mediated 
FIG. 3. Chemical structure of statins. The chemical structure of some of the most commonly used statins. Rosuvastatin is significantly more hydrophilic than atorvastatin and simvastatin, which are more lipophilic.

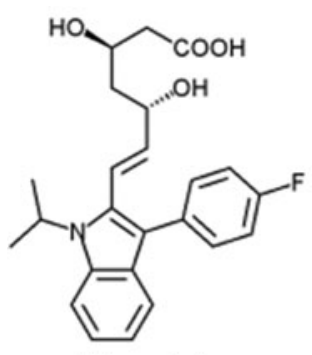

Fluvastatin<smiles>CCC(C)(C)C(=O)O[C@H]1C[C@@H](C)C=C2C=C[C@H](C)[C@H](CC[C@@H]3C[C@@H](O)CC(=O)O3)[C@H]21</smiles>

Simvastatin<smiles>CCC(C)C(=O)O[C@H]1C[C@H](O)C=C2C=C[C@H](C)[C@H](CC[C@H](O)CC(O)CC(=O)O)[C@H]2[C@H]1C(=O)O</smiles><smiles>CC(C)c1c(C(=O)Nc2ccccc2)c(-c2ccccc2)c(-c2ccc(F)cc2)n1CC[C@H](O)C[C@H](O)CC(=O)O</smiles>

Atorvastatin<smiles>CC(C)c1nc(N(C)S(C)(=O)=O)nc(-c2ccc(F)cc2)c1/C=C/[C@H](O)C[C@@H](O)CC(=O)O</smiles>

Rosuvastatin through modifications in eNOS expression, activity, and enzymatic coupling (Fig. 4). It has been shown that geranylgeranylation of the GTP-ase Rho leads to downregulation of eNOS in ECs; statin treatment inhibited GGPP formation and therefore led to enhanced eNOS expression, which was reversed by co-incubation with GGPP (56). Increased endogenous LDLs have also been shown to negatively affect eNOS mRNA expression in HUVECs, an effect reversed at the posttranscriptional level after exposure to simvastatin (65). The mechanism by which statins augment eNOS mRNA stability is an increase in eNOS mRNA polyadenylation due to alterations in the actin cytoskeleton, following Rho inhibition (51). In addition, exposure of $\mathrm{H}_{2} \mathrm{O}_{2}$-induced senescent HUVECs to statins activates the phosphatidylinositide 3-kinase (PI3K)/ Akt pathway and enhances eNOS expression (80). More recently, eNOS mRNA has been identified as a target of the micro-RNA miR-155, which is upregulated by inflammatory stimuli such as tumor necrosis factor alpha (TNF $\alpha)$. Importantly, this effect was attenuated by simvastatin, but the beneficial actions of the statin were abolished by co-incubation with mevalonate or GGPP. Interestingly, they were mimicked by inhibition of RhoA, suggesting that the mevalonate/ GGPP/RhoA pathway underlies the observed effects of simvastatin on miR-155 expression (103). The increased expression of eNOS mediated by statins translates into improved endothelial function, as evidenced in animal models of age-related (27) and high-fat-diet-induced (119) endothelial dysfunction.

In addition to augmenting eNOS expression on a transcriptional and post-transcriptional level, statins have been shown to enhance eNOS activity at a post-translational level as well. eNOS possesses several activation phosphorylation sites at serine/threonine residues. Exposure of HUVECs to fluvastatin has been demonstrated to increase phosphorylation of eNOS at the activation sites Ser-633 and Ser-1177 through protein kinase A (PKA)- and PI3K/Akt-mediated pathways, respectively (12). Statin-mediated induction of eNOS phosphorylation at Ser-1177 has been shown to rely on heat shock protein-90 recruitment of Akt to the eNOS complex in ECs (18). Atorvastatin has also been shown in ECs to increase eNOS phosphorylation at Ser-633 in an adenosine monophosphate activated protein kinase (AMPK)-mediated way (79). Moreover, ex vivo incubation of rat mesenteric resistance arteries with simvastatin induces rapid AMPKmediated eNOS phosphorylation at Ser-1177 (93). This leads to improved endothelium-dependent vasorelaxation in myograph chamber vasomotor studies, an effect reversed both by inhibition of eNOS by $N$-nitro-L-arginine methyl ester (LNAME) and by co-incubation with mevalonate. In addition to favorable modulations of its phosphorylation status, statins also increase eNOS activity at the post-translational level by inducing its dissociation from caveolin-1. Caveolae are invaginations of the cytoplasmic membrane formed primarily by the protein caveolin- 1 , which has the ability to bind eNOS and inhibit its enzymatic activity. Atorvastatin reduces caveolin-1 content and activates eNOS in ECs irrespective of the presence or absence of LDL cholesterol (18). This mechanism has also been demonstrated in apolipoprotein E (ApoE)deficient mice, where rosuvastatin reduces caveolin- 1 content and improves heart and blood pressure variability (84).

Activation of eNOS does not necessarily translate into improved NO production; if eNOS is largely uncoupled, then its phosphorylation-induced activation leads to increased production of $\mathrm{O}_{2}{ }^{-}$instead of $\mathrm{NO}$ (24). However, statins have been shown to function on multiple levels to increase both eNOS activity and its coupling status. Exposure of HUVECs to cerivastatin or fluvastatin leads to upregulation of GTPCH expression and increases $\mathrm{BH}_{4}$ bioavailability, leading to improvement of eNOS coupling $(12,42)$. In an animal diabetic model, atorvastatin administration prevents eNOS uncoupling through the same mechanism (118). We have recently demonstrated in a randomized double-blind placebocontrolled clinical trial that 3-day preoperative atorvastatin treatment (40 mg/day) of patients undergoing CABG surgery increases $\mathrm{BH}_{4}$ content and improves eNOS coupling in the human internal mammary artery (IMA) compared with the placebo group (Fig. 5) (5). This is accompanied by improved FMD of the brachial artery. Importantly, these effects are 


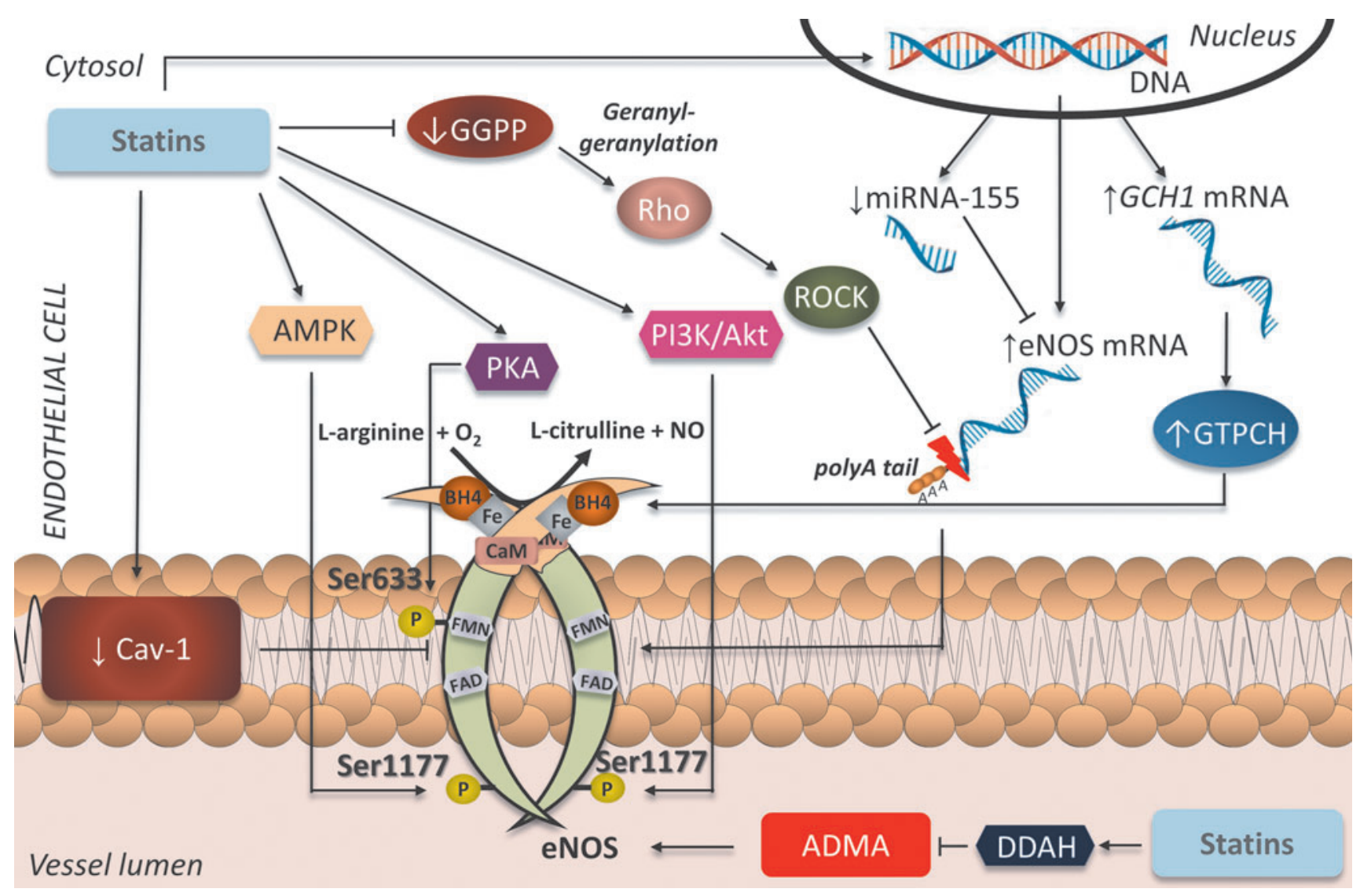

FIG. 4. Effects of statins on eNOS in ECs. By inhibiting mevalonate synthesis, statins reduce GGPP, preventing activation of Rho/ROCK and stabilizing eNOS mRNA, thus increasing eNOS expression. By reducing caveolin-1 content and circulating ADMA, and increasing phosphorylation of eNOS at activation sites Ser-633 and Ser-1177 through AMPK, Akt, and PKA, statins also increase eNOS activity. Lastly, by upregulating GTPCH, statins increase endothelial $\mathrm{BH}_{4}$ availability and restore eNOS coupling. GGPP, geranylgeranyl pyrophosphate; ROCK, Rho-associated protein kinase; GTPCH, guanosine triphosphate cyclohydrolase; AMPK, adenosine monophosphate activated protein kinase; PKA, protein kinase A; PI3K, phosphatidylinositide 3-kinase; ADMA, asymmetric dimethylarginine; EC, endothelial cell. To see this illustration in color, the reader is referred to the web version of this article at www.liebertpub.com/ars

rapid and independent of the LDL-lowering actions of atorvastatin. Ex vivo exposure of human IMAs to atorvastatin leads to upregulation of GCH1 gene, encoding for GTPCH, and a subsequent increase in vascular $\mathrm{BH}_{4}$ and total biopterin levels, effects that are reversed by co-incubation with mevalonate (5).

A possible indirect mechanism by which statins could increase eNOS activity and improve its coupling is enhanced metabolism or interference with the effects of the endogenous eNOS inhibitor ADMA. ECs exposed to ADMA exhibit an increased inflammatory response that is markedly reduced by simvastatin through extracellular receptor kinase pathways (49). Rosuvastatin treatment of spontaneously hypertensive rats has been shown to reduce circulating ADMA levels and reduce vascular oxidative stress, independently of cholesterol lowering (99). Similarly, in a rat model of pulmonary hypertension, rosuvastatin increases DDAH expression and subsequently reduces serum ADMA levels, while also increasing eNOS phosphorylation through the PI3K/Akt pathway (83). However, the results of human studies have been contradictory. Some randomized trials have demonstrated that shortterm statin treatment lowers circulating ADMA levels in humans $(61,76,112)$, while other studies have failed to find such an effect $(36,74,85,109,121)$. These discordant results could possibly be attributed to differences in the characteristics of the populations examined. Interestingly, in a small randomized trial, simvastatin failed to improve endothelial function in patients with high ADMA levels, but managed to do so in combination with oral L-arginine supplementation or in patients with low pre-existing ADMA levels (13).

\section{Effects of statins on NADPH oxidase}

NADPH oxidase is the most important source of ROS in the vasculature, both in ECs and VSMCs. It catalyzes the conversion of $\mathrm{O}_{2}$ into $\mathrm{O}_{2}{ }^{\bullet-}$ radicals, by using NADPH as an electron donor. It is a membrane-bound enzymatic complex; the components of which depend on the respective homolog of the membrane subunit present: Nox1-5 and Duox1 or 2. ECs have been shown to possess Nox2, Nox4, and Nox5, whereas Nox1, Nox4, and Nox5 have been detected in VSMCs. Nox2 is the form of the enzyme present in phagocytes; it consists of two membrane-bound subunits, $22^{\text {phox }}$ and gp91 ${ }^{\text {phox }}$-Nox2 (which constitute the cytochrome b558 complex), and four cytosolic subunits, $\mathrm{p} 40^{\text {phox }}, \mathrm{p} 47^{\text {phox }}$, p67 $7^{\text {phox }}$, and Rac1 or 2, which upon stimulation translocate to 
FIG. 5. Effects of statins on vascular $\mathrm{BH}_{4}$ and redox state of the IMA in vivo and ex vivo. Three-day preoperative administration of atorvastatin ( $40 \mathrm{mg} /$ day) in patients undergoing bypass surgery significantly reduced $\mathrm{O}_{2}{ }^{-}$ generation (A), restored eNOS coupling (B), and increased $\mathrm{BH}_{4}$ availability $(\mathrm{C})$ versus the placebo arm in the wall of the IMA. Similarly, exposure of human IMA segments to atorvastatin ex vivo increased vascular $\mathrm{BH}_{4}$ content (D) and gene expression of GCH1 (E). Inhibition of GTPCH by DAHP prevented the ex vivo effects of atorvastatin on vascular $\mathrm{BH}_{4} \quad \mathbf{( F},{ }^{*} p<0.05$ vs. control, ${ }^{* *} p<0.01$ vs. control). Adapted from Ref. (5). IMA, internal mammary artery.
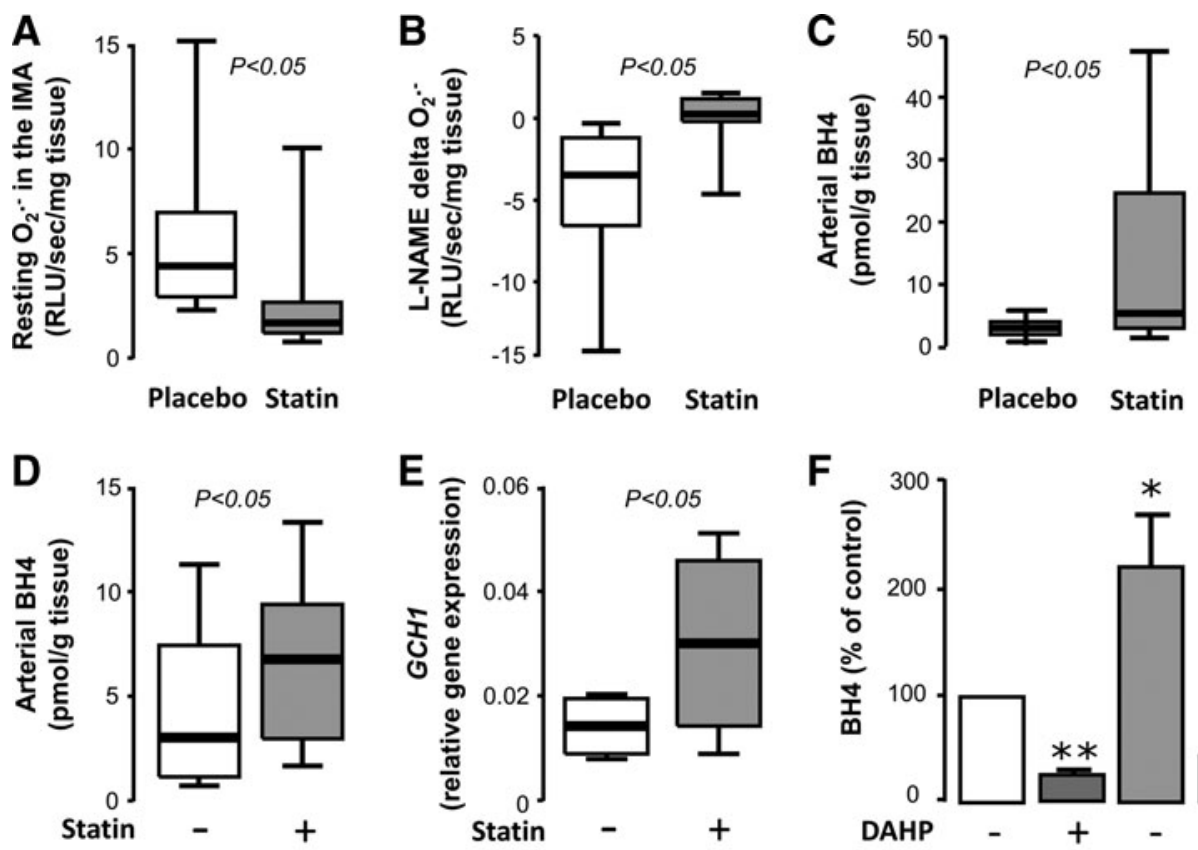

flavocytochrome b558 and lead to assembly and activation of the enzymatic complex. The activity of Nox 1 and Nox 2 can be stimulated by angiotensin II, growth hormones, and cytokines, through p47phox phosphorylation (33), whereas Nox5 is quiescent until Ca-dependent stimulation (40). On the contrary, Nox4 does not require Rac translocation for activation, but is constitutively active (33). In disease states, it is well established that elevated expression and activity of NADPH oxidase isoforms in the vasculature, together with the resulting increased ROS production, contribute to the initiation and maintenance of the atherosclerotic process. However, it should be noted that recent studies have unveiled a distinct, potentially beneficial role for the Rac1-independent Nox4 isoform in the vascular wall, by enhancing vasodilation in a $\mathrm{H}_{2} \mathrm{O}_{2}$-mediated way (91), underlying the fact that controlled ROS production in specific cellular compartments may be beneficial for vascular homeostasis, as they serve as signaling molecules that mediate multiple biological processes.

A significant amount of literature has focused on the role of statins in inhibiting NADPH oxidase activity. As mentioned previously, Rac1 activation and translocation to the membrane is necessary for the activation of Nox 1 and 2 complexes, which are abundant in vascular cells and are involved in the pathophysiology of atherosclerosis. A crucial step in Rac1 activation is its geranylgeranylation by the GGPP produced through the mevalonate pathway. Given that statins suppress the formation of isoprenoids like GGPP, a large number of studies have sought to determine whether inhibition of HMGCoA reductase could lead to attenuation of NADPH oxidase activity.

In HUVECs, statin treatment reduces $\mathrm{p} 22^{\text {phox }}$ mRNA and $\mathrm{p} 47^{\text {phox }}$ protein levels by increasing PPAR $\alpha$ activity (46). VSMCs exposed to atorvastatin show downregulation of Nox1 expression and Rac1 membrane translocation, resulting in reduced ROS generation (116). Statins are also able to blunt high glucose-induced ROS generation in porcine coronary arteries, by reducing p22 $2^{\text {phox }}$ mRNA levels (25). Withdrawal of cerivastatin in VSMCs induces the translocation of Rac1 to the membrane, with a subsequent activation of NADPH oxidase complexes and increase in $\mathrm{O}_{2}{ }^{-}$production (16). A mechanism through which NADPH oxidase exerts its effects is colocalization with ceramide and acid sphingomyelinase to form membrane rafts in the cellular membrane; in human coronary artery ECs, statin treatment prevents the oxLDLinduced formation of these membrane rafts and subsequently reduces $\mathrm{O}_{2}{ }^{-}$generation (117).

The effects of statins on NADPH oxidase have also been examined in animal models that exhibit various CVD states. Statin administration in rats has been shown to suppress NADPH oxidase activity through a mevalonate-dependent prevention of Rac activation, leading to improved vascular NO availability and subsequently improved endothelial function (113). In atherosclerotic rabbits, fluvastatin treatment prevents an increase in $\mathrm{p} 22^{\text {phox }}$ and gp $91^{\text {phox }}$ induced by highfat diet, improving endothelial function and reducing plaque size (68). Similarly, simvastatin treatment suppresses ROS generation and restores endothelial function in diabetic rat coronary arteries (105). In a normocholesterolemic hypertensive rat model, statins reduce gene expression of $\mathrm{p} 22^{\text {phox }}$ and Nox1 (116), as well as angiotensin type I receptors and $\mathrm{p} 22^{\text {phox }}$ protein levels, thereby reducing ROS production and improving endothelial function (115). In a rat model of ischemic stroke, atorvastatin pretreatment prevents increases in ROS generation and NADPH oxidase activity in the penumbra, by reducing gp91 ${ }^{\text {phox }} \mathrm{mRNA}$ levels and $\mathrm{p} 47^{\text {phox }}$ translocation to the membrane (45). On the other hand, withdrawal of statins induces endothelial dysfunction in mice, through a Rac1mediated activation of NADPH oxidase (110).

Translational studies in tissues obtained from human subjects have demonstrated the relevance of the aforementioned observations to human physiology as well. Statin treatment has been found to downregulate gp91 $91^{\text {phox }}$ levels in human internal mammary arteries obtained from patients undergoing CABG (94). In a cross-sectional study, statin 
treatment of hyperlipidemic individuals was found to be associated with reduced circulating levels of $\mathrm{gp} 91^{\text {phox }}$, as well as markers of systemic oxidative stress (88). In the Endothelial Protection, AT1 blockade and Cholesterol-Dependent Oxidative Stress (EPAS) trial, 49 patients undergoing scheduled CABG were randomized to placebo, pravastatin ( $40 \mathrm{mg} /$ day), irbesartan (150 mg/day), or both for 4 weeks (69). Statin treatment, as well as combination therapy, significantly increases eNOS and suppresses gp91 ${ }^{\text {phox }}$ expression in the left IMA, suggesting a synergistic effect on endothelial function, independently of LDL-lowering effects (69). We have recently demonstrated that short-term treatment with atorvastatin rapidly suppresses $\mathrm{O}_{2}{ }^{-}$generation and NADPH oxidase activity in SVGs from patients undergoing CABG, independently of LDL-lowering effects (Fig. 6) (6). This is also accompanied by a reduction in plasma malonyldialdehyde levels, a marker of systemic oxidative stress. Ex vivo incubation of human SVGs with atorvastatin leads to reduction in p $67^{\text {phox }}$ and Rac1 translocation to the membrane, effects that are reversed by coincubation with mevalonate (6). A similar NADPH-oxidase-suppressing mechanism has been observed by our group to be relevant to human myocardium as well (7). Figure 7 summarizes the antioxidant effects of statins through modulation of NADPH oxidase expression and activity in the endothelium.

\section{Effects of statins on other enzymatic systems and pathways in ECs}

Prostacyclin $\left(\mathrm{PGI}_{2}\right)$ is produced in ECs by the enzyme $\mathrm{PGI}_{2}$ synthase. Its precursor molecule is prostaglandin $\mathrm{H}_{2}$, itself synthesized from arachidonic acid through oxidation of fatty acids by cyclooxygenases. $\mathrm{PGI}_{2}$ is an important vasodilator and antithrombotic molecule, counterbalancing the effects of thromboxane $\mathrm{A}_{2}$. It has been recently reported that vascular $\mathrm{PGI}_{2}$ may be involved in the regulation of eNOS expres- sion (122). Importantly, Di Francesco et al. showed that cyclooxygenase-2-dependent $\mathrm{PGI}_{2}$ induced by steady laminar shear stress upregulates heme-oxygenase 1, which halts the effects of TNF $\alpha$ in human ECs (31). Given that fluvastatin has been shown to increase expression of $\mathrm{PGI}_{2}$ synthase and $\mathrm{PGI}_{2}$ in human ECs (100), this pathway may also participate in the vasoprotective effects of statins.

Statin-mediated alterations in the activity of pro-oxidant enzymes could also partially explain the beneficial antithrombotic effects of statins, as evidenced by reduced release of thromboxane A2 from aged rat aortas, in a cyclooxygenase2-mediated way (27). Release of 8-isoprostane through cyclooxygenase-2 is elevated in spontaneously hypertensive rats; this is abrogated after atorvastatin treatment, leading to an improvement of endothelial function and restoration of vascular redox state (111). Similarly, atorvastatin-induced modifications of the 5-lipoxygenase pathway (which oxidizes fatty acids into fatty acid hydroperoxides) lead to reduction of plaque vulnerability in rabbits (127).

\section{Endogenous Antioxidant Defense Mechanisms: Effects of Statins}

Due to constant exposure to ROS generated through various pathways, almost all living cells possess several enzymatic antioxidant defense systems, controlling the final ROS availability. Superoxide dismutase (SOD) is an enzyme that catalyzes the conversion of $\mathrm{O}_{2}{ }^{-}$to $\mathrm{H}_{2} \mathrm{O}_{2}$. Catalase is an enzyme located in peroxisomes, which decomposes $\mathrm{H}_{2} \mathrm{O}_{2}$ to water and $\mathrm{O}_{2}$. Glutathione (GSH) is a tripeptide that acts as an important antioxidant limiting the effects of $\mathrm{H}_{2} \mathrm{O}_{2}$; this is achieved by reducing sulfhydryl groups in cysteine residues of other proteins, thus protecting those proteins of oxidative damage. This is catalyzed by glutathione-S-transferases, as well as glutathione peroxidases (GSH-Pxs), leading to the formation of glutathione disulfide (GSSG) from two GSH
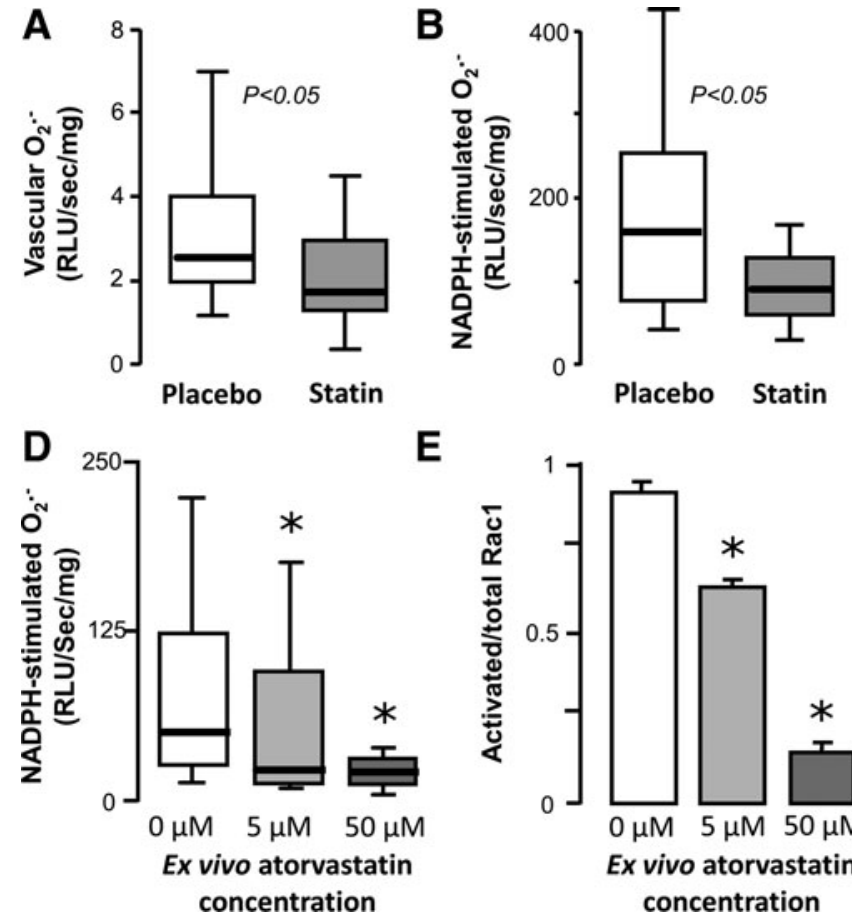

E

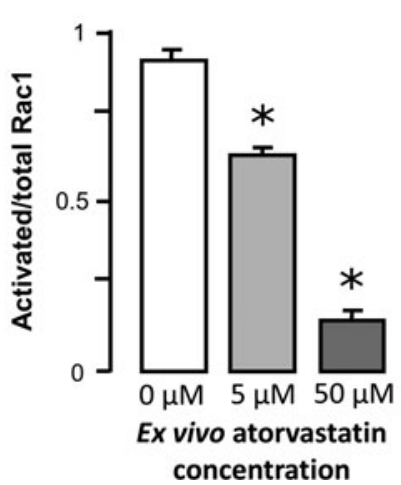

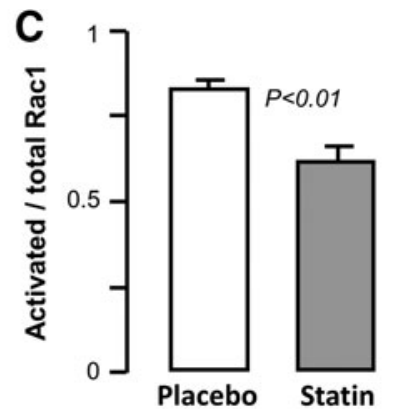

\section{F}

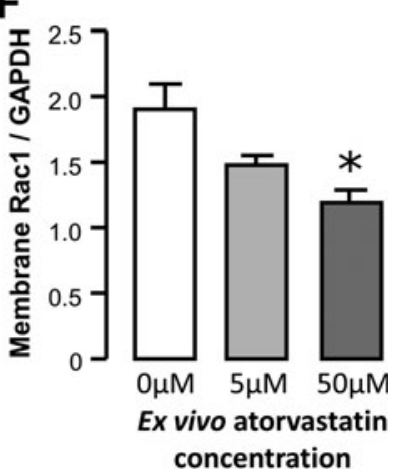

FIG. 6. Effects of statins on vascular Rac1 activation in SVGs in vivo and ex vivo. Three-day preoperative administration of atorvastatin $(40 \mathrm{mg} /$ day $)$ in patients undergoing bypass surgery significantly reduced resting (A) and NADPH-stimulated $\mathrm{O}_{2}{ }^{-}$ generation (B), as well as activation of Rac1 (C) versus the placebo arm in the vascular wall of SV grafts obtained from these patients. Similarly, exposure of human SV segments to increasing concentrations of atorvastatin ex vivo led to a dose-dependent reduction in NADPH-stimulated $\mathrm{O}_{2}{ }^{-}$generation (D), which was associated with a reduction in Rac1 activation (E) and subsequent translocation to the membrane (F). $\left({ }^{*} p<0.05\right.$ vs. no atorvastatin). Adapted from Ref. (6). SVG, saphenous vein graft. 


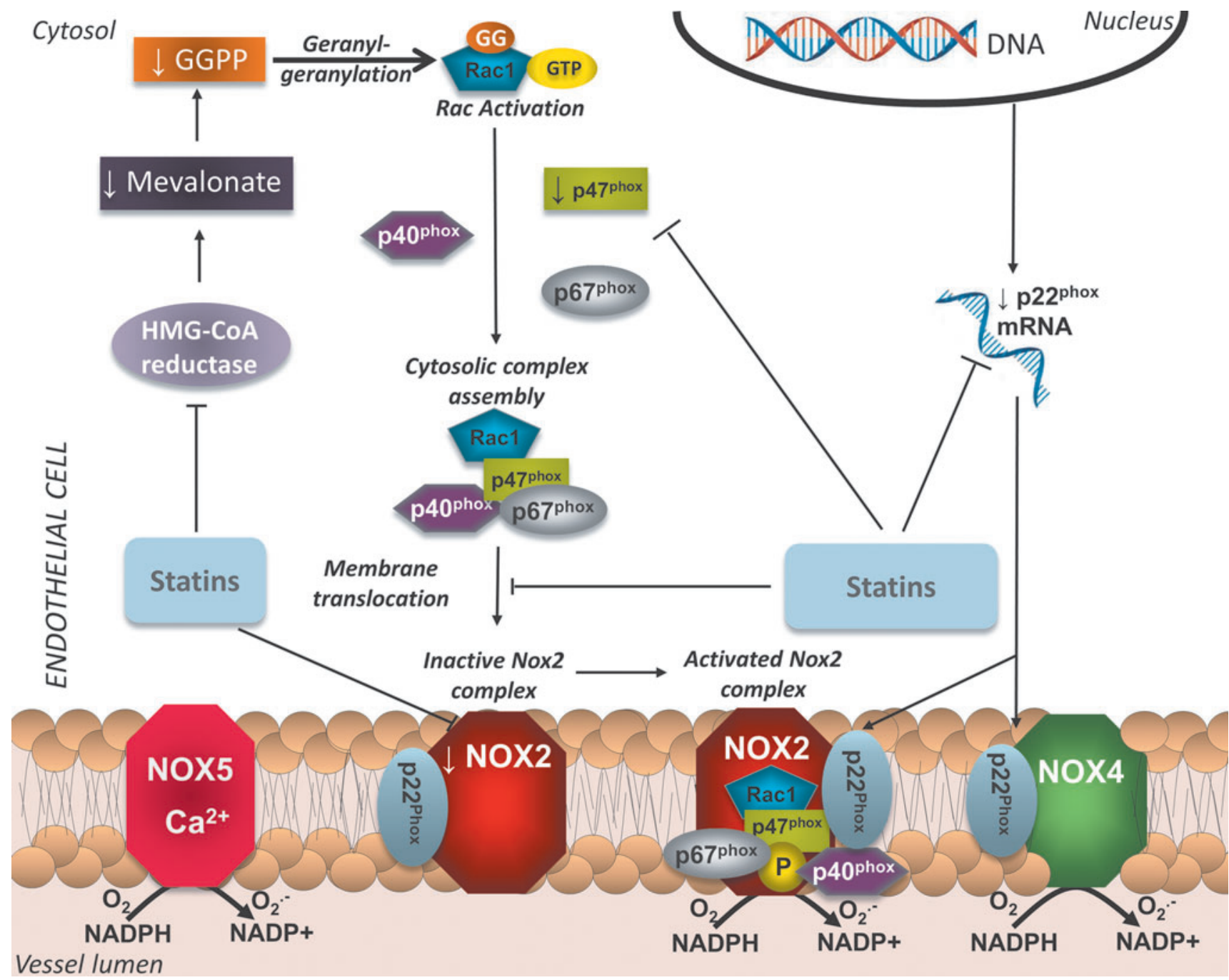

FIG. 7. Effects of statins on NADPH oxidase in EC. Statins suppress expression of p22 ${ }^{\text {phox }}$ and reduce levels of p47phox and Nox2. In addition, by lowering synthesis of GGPP, they prevent activation of Rac1 and translocation to the membrane, thus preventing activation of the Nox2 complex in the endothelium. To see this illustration in color, the reader is referred to the web version of this article at www.liebertpub.com/ars

molecules; GSH can be replenished through the effects of glutathione reductase. The GSH/GSSG ratio is widely used as a marker of cellular redox state. Paraoxonase is an enzyme involved in protection against oxidation of the LDL molecule. Other antioxidant enzymatic systems are also present in cells, such as thioredoxins, peroxiredoxins, and so on.

Statins have been shown to exert beneficial effects in the vasculature not only through suppression of pro-oxidant enzyme but also through enhanced levels and activity of endogenous antioxidant systems, in both experimental models and human studies. Simvastatin can partially restore renal levels of all three major cellular antioxidant defense systems (SOD, GSH-Px, and catalase) and reduce the levels of oxidative damage biomarkers in diabetic animals $(53,128)$. It has also been shown to improve endothelial function by increasing SOD levels in rats chronically treated with the eNOS inhibitor LNAME (86). In addition, the beneficial effects of atorvastatin on plaque size reduction in animals fed an atherogenic diet are potentially mediated by an increase in circulating paraoxonase levels (97).
The effects of statins on catalase levels and activity have been demonstrated in a number of studies. Rat aortic VSMCs and senescent HUVECs show increased gene expression and protein levels of catalase after atorvastatin treatment (116), an effect mediated by the PI3K/Akt pathway (80). In animal models of hypertension and diabetes, statins elevate aortic catalase expression through a sirtuin-1-dependent pathway $(80,116)$. A statin-induced increase in catalase levels has also been demonstrated in human abdominal aortic aneurysms (87).

\section{Effects of Statins on Redox-Sensitive Transcriptional Pathways}

It is well established that a major mechanism through which increased production of ROS promotes atherosclerosis is the triggering of redox-sensitive transcriptional pathways in the vascular endothelium (Fig. 8). These pathways regulate the production of pro-inflammatory, pro-atherogenic cytokines, and cellular components, which enhance oxLDL and 


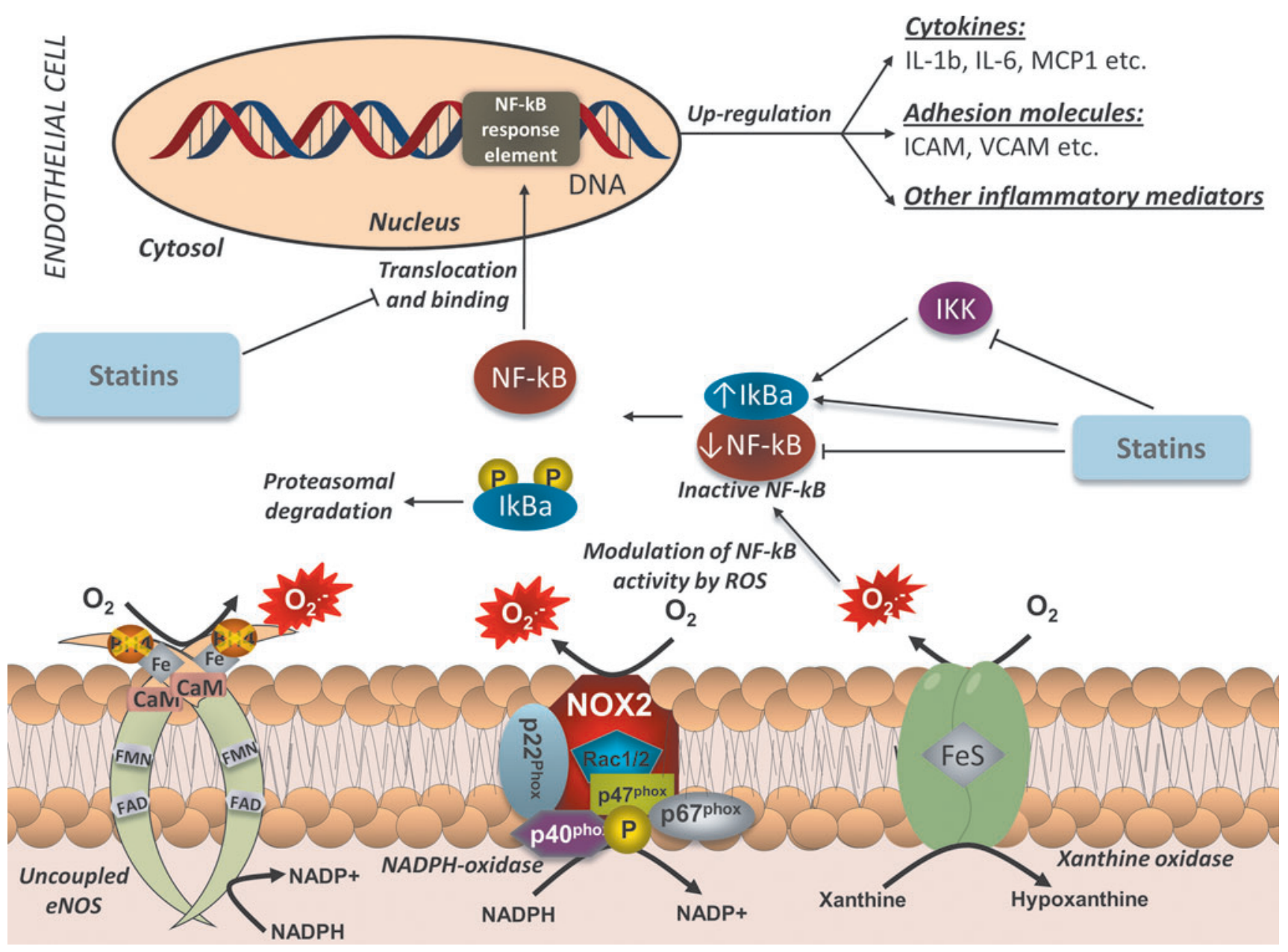

FIG. 8. Effects of statins on redox-sensitive transcriptional pathways in ECs. Statins reduce ROS generation by suppressing pro-oxidant enzymes and restoring eNOS coupling, thus preventing ROS-mediated activation of NF- $\kappa$ B. In addition, statins increase levels of the inhibitor $\mathrm{I} \kappa \mathrm{B} \alpha$, while at the same time suppressing IKK and lowering the levels, activity, and binding capacity of NF- $\kappa \mathrm{B}$. This prevents the NF- $\kappa \mathrm{B}$-mediated transcription of pro-inflammatory cytokines and adhesion molecules in ECs. NF- $\kappa$ B, nuclear factor kappa B; $\mathrm{I} \kappa \mathrm{B} \alpha, \mathrm{NF}-\kappa \mathrm{B}$ inhibitor alpha; IKK, I $\kappa \mathrm{B}$ kinase; ICAM, intercellular adhesion molecule; VCAM, vascular cell adhesion molecule. To see this illustration in color, the reader is referred to the web version of this article at www.liebertpub.com/ars

macrophage infiltration, as well as VSMC proliferation and migration to the intima. One of the most important redoxsensitive pathways is the NF- $\kappa \mathrm{B}$ pathway. NF- $\kappa \mathrm{B}$ is a transcription factor that controls the expression of a large number of pro-inflammatory genes. In its inactivated form, NF- $\kappa \mathrm{B}$ is located in the cytosol, bound to its inhibitor $(\mathrm{I} \kappa \mathrm{B} \alpha)$. While $\mathrm{H}_{2} \mathrm{O}_{2}$ had been initially proposed as being able to directly activate NF- $\kappa \mathrm{B}$ (107), it is now widely accepted that ROS have the ability to indirectly modulate NF- $\kappa \mathrm{B}$ function (70). Proinflammatory mediators, such as $\mathrm{TNF} \alpha$, have been shown to activate the $\mathrm{I} \kappa \mathrm{B}$ kinase (IKK), which phosphorylates IkB and leads to its ubiquination and degradation, thus freeing the NF- $\kappa$ B molecule. Consequently, NF- $\kappa$ B translocates to the nucleus and binds to its response elements, initiating the transcription of pro-atherogenic mediators, such as IL-6, $\mathrm{TNF} \alpha$, the adhesion molecules VCAM-1 and intercellular adhesion molecule (ICAM)-1, and others. Another proinflammatory transcription factor that can be triggered by ROS is activator protein-1 (AP-1). Like NF- $\kappa \mathrm{B}, \mathrm{AP}-1$ controls the expression of genes involved in inflammatory processes, cellular proliferation, and apoptosis, and has a role in the atherosclerotic process.

The role of statins as potential inhibitors of NF- $\kappa$ B has been investigated in cell models, where NF- $\kappa$ B activity has been induced through a variety of different stimuli. Exposure of VSMCs to atorvastatin prevents TNF $\alpha$ - and angiotensin IIinduced activation of $\mathrm{NF}-\kappa \mathrm{B}$ and the subsequent upregulation of inflammatory mediators, effects prevented by FPP and GGPP (77). Fluvastatin also appears to attenuate CRPinduced activation of NF- $\kappa$ B both in ECs (114) and VSMCs (41). Both simvastatin and atorvastatin attenuate oxLDLinduced activation of $\mathrm{NF}-\kappa \mathrm{B}$ in human coronary artery ECs (57). These statin-mediated effects have also been demonstrated in animal models of CVD. Simvastatin treatment reduces NF- $\kappa$ B activity in both the atherosclerotic plaques and circulating mononuclear cells of diet-induced atherosclerotic animals, independently of lipid-lowering effects (43). Similarly, administration of cerivastatin significantly reduces cardiac activation of NF- $\kappa$ B induced by angiotensin II, without affecting cholesterol levels (29). The LDL-independent, 
anti-inflammatory role of statins has also been extensively explored in cell models where atherosclerosis-like inflammation has been induced by infection with a pathogen. In an EC and a VSMC model of Chlamydia pneumoniae-induced inflammation, cerivastatin significantly attenuates the upregulation of inflammatory mediators, through suppression of NF- $\kappa$ B activation $(30,52)$. Similarly, in HUVECs infected with cytomegalovirus, exposure to fluvastatin attenuates NF- $\kappa \mathrm{B}$ activation, leading to reduced viral replication (89).

Statin interference of the NF- $\kappa \mathrm{B}$ pathway can also have a crucial role in preventing monocyte infiltration, foam cell formation, and VSMC proliferation. Simvastatin inhibits in a time- and dose-dependent way the TNF $\alpha$-induced upregulation of ICAM and VCAM-1 in HUVECs by reducing NF- $\kappa$ B activation; this leads to reduced monocyte-EC interactions (123). Importantly, in vitro exposure of human monocytes to pravastatin abrogates LDL-induced activation of NF- $\kappa \mathrm{B}$ and subsequent expression of inflammatory mediators (124). In addition, atorvastatin inhibits IL-18-induced migration of aortic VSMCs through AP-1 and NF- $\kappa$ B inactivation (21).

Various mechanisms have been proposed to explain the observed reduction in NF- $\kappa$ B activity triggered by statins. It has been demonstrated that statins induce upregulation of gene expression of $\mathrm{I} \kappa \mathrm{B} \alpha$ in ECs as well as downregulation of expression of NF- $\kappa \mathrm{B}$ and reduction of its protein-binding capacity in both ECs and VSMCs, thus leading to an overall reduction in NF- $\kappa \mathrm{B}$ activity in vascular cells (32). In addition, statins have also been shown to reduce ROS-mediated activation of NF- $\kappa$ B in monocytes through a reduction in IKK activity (78). An IKK-independent pathway that involves inhibition of PI3K/Akt signaling has also been demonstrated in human ECs (44).

The ability of statins to suppress NF- $\kappa$ B signaling has also been shown in clinical studies. In a small, nonrandomized study, 3 months of pravastatin treatment ( $40 \mathrm{mg} /$ day) before scheduled carotid endarterectomy led to a more stabilized phenotype of the carotid plaque, as evidenced by reduced lipid and inflammatory content, characterized by reduced activation of NF- $\kappa \mathrm{B}$ (26). In the human abdominal aortic aneurysm wall, simvastatin suppresses ROS generation and NF$\kappa \mathrm{B}$ activity (87). In a randomized trial, atorvastatin treatment ( $80 \mathrm{mg}$ /day) 1 month before endarterectomy was associated with reduced NF- $\kappa$ B activation in circulating mononuclear cells and the carotid plaque, coupled with reduced inflammatory gene expression and cell infiltration of the plaque (78).

A major transcriptional pathway that is pivotal to the cellular antioxidant response is that of the transcription factor Nrf2 [Nuclear factor (erythroid-derived 2)-like 2]. In its inactivated form, Nrf2 is located in the cytoplasm, bound to the proteins Cullin 3 and Keap1 (Kelch like-ECH-associated protein 1). Keap1 possesses cysteine residues, which are sensitive to ROS modifications due to their sulfhydryl group $(-\mathrm{SH})$. Oxidation of these - $\mathrm{SH}$ groups dissociates the Cullin3/Keap1 complex from Nrf2, which translocates to the nucleus and initiates transcription of genes encoding for endogenous antioxidant defense proteins. Simvastatin has been shown to activate Nrf2 through the PI3K/Akt pathway and subsequently suppress ROS generation in primary mouse embryonic fibroblasts (23). Similarly, fluvastatin significantly increases Nrf2 nuclear translocation in human coronary artery SMCs through the same intracellular pathway, leading to upregulation of antioxidant enzymes and reduction in ROS production (62).

\section{Effects of Statins on Gene Expression Profile of Vascular Cells}

Gene expression profiling through gene chip microarray analysis has revolutionized the way researchers explore disease and treatment. By identifying gene targets that are differentially regulated in disease states or after intervention, we can gain substantial insights into the causation and processes underlying pathophysiological conditions. This allows for identification of novel therapeutic targets or improvement of existing treatment strategies. In this context, the effects of statins on the endothelial transcriptome have been the focus of significant research in the last years, in an effort to better understand the mechanisms that underlie the multifaceted pleiotropic actions of these compounds.

Transcriptome analysis of HUVECs exposed to atorvastatin or pravastatin reveals a shift toward a less inflammatory, prothrombotic, and vasoconstricting gene expression profile; this is evidenced by downregulation of IL-8, monocyte chemoattractant protein-1, plasminogen activator inhibitor-1, and endothelin-1, as well as upregulation of thrombomodulin and eNOS (71). Human coronary artery SMCs have also been shown to have significant upregulation of thrombomodulin after statin treatment (72). Two different studies, the first in human pulmonary artery ECs exposed to simvastatin for $16 \mathrm{~h}$ (48) and the other in aortas of ApoE-deficient, high-cholesteroldiet mice treated with pravastatin for 6 weeks (59), showed very similar results in relation to changes in gene expression profile; in both studies, statin treatment activated genes related to cytoskeleton organization. This means that both acute and chronic statin treatment led to modifications in cytoskeleton proteins, which could mediate the beneficial effects of statins on endothelial function. A very interesting study reveals that more than $20 \%$ of human coronary artery EC genes affected by simvastatin treatment have a currently unknown physiological function (126). The same study shows a significant downregulation of genes involved in proliferation and cell cycle control (126). These results could potentially explain the protective effects of statins against neointimal formation, while also highlighting the fact that a significant portion of the mechanisms that underlie their pleiotropic actions on human endothelium is still incompletely understood.

\section{Adverse Effects of Statin Treatment}

Like any other medication, statins are not devoid of adverse effects. The most significant side effects associated with statin treatment are elevation of liver enzymes and muscle-related complaints, which can range from myalgias to myositis and rhabdomyolysis (39). The mechanisms that underlie these effects have been extensively explored, and mostly relate to mitochondrial defects due to depletion of ubiquinone (Coenzyme Q10), the production of which depends on the mevalonate pathway. The appearance of these side effects depends on the genetic predisposition of the individual but is also largely dose dependent (41). Therefore, care should be taken by clinicians when using statin therapy to achieve optimal treatment targets while at the same time avoiding onset of adverse effects.

\section{Conclusions}

The use of statins has become a key strategy to reduce cardiovascular risk both in primary and secondary prevention. 
Further to their lipid-lowering properties, statins also have a number of direct, or pleiotropic, effects on vascular function, suppressing atherogenesis and in some cases may even lead to atherosclerotic plaque regression. Over the last decade, the vascular endothelium has been identified as one of the primary targets for the antiatherogenic/pleiotropic effects of statins. Statins have the ability to restore the physiological balance between $\mathrm{NO}$ and ROS production in the vascular endothelium, through a number of LDL-dependent and -independent effects. They increase the expression, activity, and enzymatic coupling of eNOS, the main source of $\mathrm{O}_{2}{ }^{--}$ radicals in the human vascular endothelium, leading to increased NO biosynthesis. At the same time, they suppress the activity of pro-oxidant enzymes (such as NADPH oxidase, uncoupled eNOS, and others) and enhance the efficiency of endogenous antioxidant defense systems in the vascular endothelium, leading to a net reduction of ROS bioavailability. By restoring the balance between $\mathrm{NO}$ and ROS in the vascular endothelium, statins also control the activation of key redox-sensitive transcriptional pathways with a key role in the control of vascular inflammation, and they also prevent the proliferation/migration of VSMCs by suppressing atherogenesis.

\section{Future Perspectives}

There are several remaining issues that need to be addressed regarding the biological role of statins as regulators of vascular redox state. Their indirect effects on vascular redox state (e.g., by modifying the biology of perivascular adipose tissue that exerts paracrine effects on the vascular wall) should be further explored in the future. At a clinical level, the beneficial role of statin treatment in vascular disease pathogenesis and especially in atherosclerosis is clear. Statins are now the corn stone of all therapeutic strategies in both primary and secondary cardiovascular prevention (101). Their use is also clearly indicated in ACSs, as they stabilize atherosclerotic plaques and they improve survival (3). However, given the complex biological effects of statins, it is hard to support that these clinical effects are primarily due to their direct or indirect "antioxidant capacity." Further research is required to examine whether statins are clinically effective in other CVDs with significant involvement of ROS in their pathogenesis. That would expand further their already wide clinical indications.

Finally, the ability of statins to exert their biological effects in the vascular endothelium independently of their primary pharmacological action, which is LDL-lowering effect, could serve as a "pharmacological model" for the development of novel antioxidant strategies that aim to control the intracellular balance between production/elimination of ROS beyond their simple chemical scavenging in the vascular endothelium. These clever strategies should aim to mimic the pleiotropic effects of statins on the vascular endothelium, to achieve the appropriate balanced regulation of vascular redox signaling in the human endothelium.

\section{Acknowledgments}

This study was funded by the British Heart Foundation (FS/11/66/28855). C.A. and M.M. also acknowledge support from the BHF Centre of Research Excellence, Oxford (RE/08/ 004).

\section{References}

1. The Post Coronary Artery Bypass Graft Trial Investigators. The effect of aggressive lowering of low-density lipoprotein cholesterol levels and low-dose anticoagulation on obstructive changes in saphenous-vein coronary-artery bypass grafts. N Engl J Med 336: 153-162, 1997.

2. Prevention of cardiovascular events and death with pravastatin in patients with coronary heart disease and a broad range of initial cholesterol levels. The Long-Term Intervention with Pravastatin in Ischaemic Disease (LIPID) Study Group. N Engl J Med 339: 1349-1357, 1998.

3. Afilalo J, Majdan AA, and Eisenberg MJ. Intensive statin therapy in acute coronary syndromes and stable coronary heart disease: a comparative meta-analysis of randomised controlled trials. Heart 93: 914-921, 2007.

4. Alp NJ, Mussa S, Khoo J, Cai S, Guzik T, Jefferson A, Goh N, Rockett KA, and Channon KM. Tetrahydrobiopterindependent preservation of nitric oxide-mediated endothelial function in diabetes by targeted transgenic GTP-cyclohydrolase I overexpression. J Clin Invest 112: 725-735, 2003.

5. Antoniades C, Bakogiannis C, Leeson P, Guzik TJ, Zhang MH, Tousoulis D, Antonopoulos AS, Demosthenous M, Marinou K, Hale A, Paschalis A, Psarros C, Triantafyllou C, Bendall J, Casadei B, Stefanadis C, and Channon KM. Rapid, direct effects of statin treatment on arterial redox state and nitric oxide bioavailability in human atherosclerosis via tetrahydrobiopterin-mediated endothelial nitric oxide synthase coupling. Circulation 124: 335-345, 2011.

6. Antoniades C, Bakogiannis C, Tousoulis D, Reilly S, Zhang $\mathrm{MH}$, Paschalis A, Antonopoulos AS, Demosthenous M, Miliou A, Psarros C, Marinou K, Sfyras N, Economopoulos G, Casadei B, Channon KM, and Stefanadis $C$. Preoperative atorvastatin treatment in $C A B G$ patients rapidly improves vein graft redox state by inhibition of Rac1 and NADPH-oxidase activity. Circulation 122: S66-S73, 2010.

7. Antoniades C, Demosthenous M, Reilly S, Margaritis M, Zhang MH, Antonopoulos A, Marinou K, Nahar K, Jayaram R, Tousoulis D, Bakogiannis C, Sayeed R, Triantafyllou C, Koumallos N, Psarros C, Miliou A, Stefanadis C, Channon KM, and Casadei B. Myocardial redox state predicts in-hospital clinical outcome after cardiac surgery effects of short-term pre-operative statin treatment. J Am Coll Cardiol 59: 60-70, 2012.

8. Antoniades C, Shirodaria C, Leeson P, Antonopoulos A, Warrick N, Van-Assche T, Cunnington C, Tousoulis D, Pillai R, Ratnatunga C, Stefanadis C, and Channon KM. Association of plasma asymmetrical dimethylarginine (ADMA) with elevated vascular superoxide production and endothelial nitric oxide synthase uncoupling: implications for endothelial function in human atherosclerosis. Eur Heart J 30: 1142-1150, 2009.

9. Antoniades C, Van-Assche T, Shirodaria C, Diesch J, Antonopoulos AS, Lee J, Cunnington C, Tousoulis D, Stefanadis C, Casadei B, Taggart D, Channon KM, and Leeson P. Preoperative SCD40L levels predict risk of atrial fibrillation after off-pump coronary artery bypass graft surgery. Circulation 120: S170-S176, 2009.

10. Antonopoulos AS, Antoniades C, Tousoulis D, Bakogiannis C, Demosthenous M, Psarros C, and Stefanadis C. Novel therapeutic strategies targeting vascular redox in human atherosclerosis. Recent Pat Cardiovasc Drug Discov 4: 76-87, 2009. 
11. Antonopoulos AS, Margaritis M, Shirodaria C, and Antoniades C. Translating the effects of statins: from redox regulation to suppression of vascular wall inflammation. Thromb Haemost 108: 840-848, 2012.

12. Aoki C, Nakano A, Tanaka S, Yanagi K, Ohta S, Jojima T, Kasai K, Takekawa H, Hirata K, and Hattori Y. Fluvastatin upregulates endothelial nitric oxide synthase activity via enhancement of its phosphorylation and expression and via an increase in tetrahydrobiopterin in vascular endothelial cells. Int J Cardiol 156: 55-61, 2012.

13. Boger GI, Rudolph TK, Maas R, Schwedhelm E, Dumbadze E, Bierend A, Benndorf RA, and Boger RH. Asymmetric dimethylarginine determines the improvement of endothelium-dependent vasodilation by simvastatin: effect of combination with oral L-arginine. J Am Coll Cardiol 49: 2274-2282, 2007.

14. Boger RH, Maas R, Schulze F, and Schwedhelm E. Asymmetric dimethylarginine (ADMA) as a prospective marker of cardiovascular disease and mortality-an update on patient populations with a wide range of cardiovascular risk. Pharmacol Res 60: 481-487, 2009.

15. Boger RH, Sydow K, Borlak J, Thum T, Lenzen H, Schubert B, Tsikas D, and Bode-Boger SM. LDL cholesterol upregulates synthesis of asymmetrical dimethylarginine in human endothelial cells: involvement of S-adenosylmethioninedependent methyltransferases. Circ Res 87: 99-105, 2000.

16. Brandes RP, Beer S, Ha T, and Busse R. Withdrawal of cerivastatin induces monocyte chemoattractant protein 1 and tissue factor expression in cultured vascular smooth muscle cells. Arterioscler Thromb Vasc Biol 23: 1794-1800, 2003.

17. Braunwald E. Biomarkers in heart failure. N Engl J Med 358: 2148-2159, 2008.

18. Brouet A, Sonveaux P, Dessy C, Moniotte S, Balligand JL, and Feron O. Hsp90 and caveolin are key targets for the proangiogenic nitric oxide-mediated effects of statins. Circ Res 89: 866-873, 2001.

19. Cannon CP, Steinberg BA, Murphy SA, Mega JL, and Braunwald E. Meta-analysis of cardiovascular outcomes trials comparing intensive versus moderate statin therapy. J Am Coll Cardiol 48: 438-445, 2006.

20. Cardounel AJ, Xia Y, and Zweier JL. Endogenous methylarginines modulate superoxide as well as nitric oxide generation from neuronal nitric-oxide synthase: differences in the effects of monomethyl- and dimethylarginines in the presence and absence of tetrahydrobiopterin. J Biol Chem 280: 7540-7549, 2005.

21. Chandrasekar B, Mummidi S, Mahimainathan L, Patel DN, Bailey SR, Imam SZ, Greene WC, and Valente AJ. Interleukin-18-induced human coronary artery smooth muscle cell migration is dependent on NF-kappaB- and AP-1mediated matrix metalloproteinase- 9 expression and is inhibited by atorvastatin. J Biol Chem 281: 15099-15109, 2006.

22. Channon KM and Guzik TJ. Mechanisms of superoxide production in human blood vessels: relationship to endothelial dysfunction, clinical and genetic risk factors. J Physiol Pharmacol 53: 515-524, 2002.

23. Chartoumpekis D, Ziros PG, Psyrogiannis A, Kyriazopoulou V, Papavassiliou AG, and Habeos IG. Simvastatin lowers reactive oxygen species level by Nrf2 activation via $\mathrm{PI} 3 \mathrm{~K} /$ Akt pathway. Biochem Biophys Res Commun 396: 463-466, 2010.

24. Chen CA, Druhan LJ, Varadharaj S, Chen YR, and Zweier JL. Phosphorylation of endothelial nitric-oxide synthase regulates superoxide generation from the enzyme. $J$ Biol Chem 283: 27038-27047, 2008.

25. Christ M, Bauersachs J, Liebetrau C, Heck M, Gunther A, and Wehling M. Glucose increases endothelial-dependent superoxide formation in coronary arteries by $\mathrm{NAD}(\mathrm{P}) \mathrm{H}$ oxidase activation: attenuation by the 3-hydroxy-3methylglutaryl coenzyme A reductase inhibitor atorvastatin. Diabetes 51: 2648-2652, 2002.

26. Crisby M, Nordin-Fredriksson G, Shah PK, Yano J, Zhu J, and Nilsson J. Pravastatin treatment increases collagen content and decreases lipid content, inflammation, metalloproteinases, and cell death in human carotid plaques: implications for plaque stabilization. Circulation 103: 926933, 2001.

27. de Sotomayor MA, Perez-Guerrero C, Herrrera MD, Jimenez L, Marin R, Marhuenda E, and Andriantsitohaina $\mathrm{R}$. Improvement of age-related endothelial dysfunction by simvastatin: effect on $\mathrm{NO}$ and COX pathways. Br J Pharmacol 146: 1130-1138, 2005.

28. Deanfield JE, Halcox JP, and Rabelink TJ. Endothelial function and dysfunction: testing and clinical relevance. Circulation 115: 1285-1295, 2007.

29. Dechend R, Fiebeler A, Park JK, Muller DN, Theuer J, Mervaala E, Bieringer M, Gulba D, Dietz R, Luft FC, and Haller H. Amelioration of angiotensin II-induced cardiac injury by a 3-hydroxy-3-methylglutaryl coenzyme a reductase inhibitor. Circulation 104: 576-581, 2001.

30. Dechend R, Gieffers J, Dietz R, Joerres A, Rupp J, Luft FC, and Maass M. Hydroxymethylglutaryl coenzyme A reductase inhibition reduces Chlamydia pneumoniae-induced cell interaction and activation. Circulation 108: 261-265, 2003.

31. Di Francesco L, Totani L, Dovizio M, Piccoli A, Di Francesco A, Salvatore T, Pandolfi A, Evangelista V, Dercho RA, Seta F, and Patrignani P. Induction of prostacyclin by steady laminar shear stress suppresses tumor necrosis factor-alpha biosynthesis via heme oxygenase- 1 in human endothelial cells. Circ Res 104: 506-513, 2009.

32. Dichtl W, Dulak J, Frick M, Alber HF, Schwarzacher SP, Ares MP, Nilsson J, Pachinger O, and Weidinger F. HMGCoA reductase inhibitors regulate inflammatory transcription factors in human endothelial and vascular smooth muscle cells. Arterioscler Thromb Vasc Biol 23: 58-63, 2003.

33. Dikalov SI, Dikalova AE, Bikineyeva AT, Schmidt HH, Harrison DG, and Griendling KK. Distinct roles of Nox1 and Nox4 in basal and angiotensin II-stimulated superoxide and hydrogen peroxide production. Free Radic Biol Med 45: 1340-1351, 2008.

34. Dikalova AE, Bikineyeva AT, Budzyn K, Nazarewicz RR, McCann L, Lewis W, Harrison DG, and Dikalov SI. Therapeutic targeting of mitochondrial superoxide in hypertension. Circ Res 107: 106-116, 2010.

35. Domanski M, Tian X, Fleg J, Coady S, Gosen C, Kirby R, Sachdev V, Knatterud G, and Braunwald E. Pleiotropic effect of lovastatin, with and without cholestyramine, in the post coronary artery bypass graft (Post CABG) trial. Am J Cardiol 102: 1023-1027, 2008.

36. Eid HM, Eritsland J, Larsen J, Arnesen H, and Seljeflot I. Increased levels of asymmetric dimethylarginine in populations at risk for atherosclerotic disease. Effects of pravastatin. Atherosclerosis 166: 279-284, 2003.

37. Frei B, Stocker R, and Ames BN. Antioxidant defenses and lipid peroxidation in human blood plasma. Proc Natl Acad Sci USA 85: 9748-9752, 1988. 
38. Gokce N, Keaney JF Jr., Hunter LM, Watkins MT, Menzoian JO, and Vita JA. Risk stratification for postoperative cardiovascular events via noninvasive assessment of endothelial function: a prospective study. Circulation 105: 1567-1572, 2002.

39. Golomb BA and Evans MA. Statin adverse effects: a review of the literature and evidence for a mitochondrial mechanism. Am J Cardiovasc Drugs 8: 373-418, 2008.

40. Guzik TJ, Chen W, Gongora MC, Guzik B, Lob HE, Mangalat D, Hoch N, Dikalov S, Rudzinski P, Kapelak B, Sadowski J, and Harrison DG. Calcium-dependent NOX5 nicotinamide adenine dinucleotide phosphate oxidase contributes to vascular oxidative stress in human coronary artery disease. J Am Coll Cardiol 52: 1803-1809, 2008.

41. Hattori Y, Matsumura M, and Kasai K. Vascular smooth muscle cell activation by C-reactive protein. Cardiovasc Res 58: 186-195, 2003.

42. Hattori Y, Nakanishi N, Akimoto K, Yoshida M, and Kasai K. HMG-CoA reductase inhibitor increases GTP cyclohydrolase I mRNA and tetrahydrobiopterin in vascular endothelial cells. Arterioscler Thromb Vasc Biol 23: 176-182, 2003.

43. Hernandez-Presa MA, Ortego M, Tunon J, Martin-Ventura JL, Mas S, Blanco-Colio LM, Aparicio C, Ortega L, GomezGerique J, Vivanco F, and Egido J. Simvastatin reduces NFkappaB activity in peripheral mononuclear and in plaque cells of rabbit atheroma more markedly than lipid lowering diet. Cardiovasc Res 57: 168-177, 2003.

44. Holschermann H, Schuster D, Parviz B, Haberbosch W, Tillmanns $\mathrm{H}$, and Muth $\mathrm{H}$. Statins prevent NF-kappaB transactivation independently of the IKK-pathway in human endothelial cells. Atherosclerosis 185: 240-245, 2006.

45. Hong H, Zeng JS, Kreulen DL, Kaufman DI, and Chen AF. Atorvastatin protects against cerebral infarction via inhibition of NADPH oxidase-derived superoxide in ischemic stroke. Am J Physiol Heart Circ Physiol 291: H2210-H2215, 2006.

46. Inoue I, Goto S, Mizotani K, Awata T, Mastunaga T, Kawai S, Nakajima T, Hokari S, Komoda T, and Katayama S. Lipophilic HMG-CoA reductase inhibitor has an antiinflammatory effect: reduction of MRNA levels for interleukin-1beta, interleukin-6, cyclooxygenase-2, and p22phox by regulation of peroxisome proliferator-activated receptor alpha (PPARalpha) in primary endothelial cells. Life Sci 67: 863-876, 2000.

47. Istvan ES and Deisenhofer J. Structural mechanism for statin inhibition of HMG-CoA reductase. Science 292: 11601164, 2001.

48. Jacobson JR, Dudek SM, Birukov KG, Ye SQ, Grigoryev DN, Girgis RE, and Garcia JG. Cytoskeletal activation and altered gene expression in endothelial barrier regulation by simvastatin. Am J Respir Cell Mol Biol 30: 662-670, 2004.

49. Jiang JL, Wang S, Li NS, Zhang XH, Deng HW, and Li YJ. The inhibitory effect of simvastatin on the ADMA-induced inflammatory reaction is mediated by MAPK pathways in endothelial cells. Biochem Cell Biol 85: 66-77, 2007.

50. Koh KK, Sakuma I, and Quon MJ. Differential metabolic effects of distinct statins. Atherosclerosis 215: 1-8, 2011.

51. Kosmidou I, Moore JP, Weber M, and Searles CD. Statin treatment and 3' polyadenylation of eNOS mRNA. Arterioscler Thromb Vasc Biol 27: 2642-2649, 2007.

52. Kothe H, Dalhoff K, Rupp J, Muller A, Kreuzer J, Maass M, and Katus HA. Hydroxymethylglutaryl coenzyme A reductase inhibitors modify the inflammatory response of human macrophages and endothelial cells infected with Chlamydia pneumoniae. Circulation 101: 1760-1763, 2000.

53. Kurusu A, Shou I, Nakamura S, Fukui M, Shirato I, and Tomino Y. Effects of the new hydroxy-3-methylglutaryl coenzyme a reductase inhibitor fluvastatin on anti-oxidant enzyme activities and renal function in streptozotocin-induced diabetic rats. Clin Exp Pharmacol Physiol 27: 767-770, 2000.

54. Landmesser U, Bahlmann F, Mueller M, Spiekermann S, Kirchhoff N, Schulz S, Manes C, Fischer D, de Groot K, Fliser D, Fauler G, Marz W, and Drexler H. Simvastatin versus ezetimibe: pleiotropic and lipid-lowering effects on endothelial function in humans. Circulation 111: 2356-2363, 2005.

55. Landmesser U, Hornig B, and Drexler H. Endothelial function: a critical determinant in atherosclerosis? Circulation 109: II27-II33, 2004.

56. Laufs U and Liao JK. Post-transcriptional regulation of endothelial nitric oxide synthase mRNA stability by Rho GTPase. J Biol Chem 273: 24266-24271, 1998.

57. Li D, Chen H, Romeo F, Sawamura T, Saldeen T, and Mehta JL. Statins modulate oxidized low-density lipoprotein-mediated adhesion molecule expression in human coronary artery endothelial cells: role of LOX-1. J Pharmacol Exp Ther 302: 601-605, 2002.

58. Liu PY, Liu YW, Lin LJ, Chen JH, and Liao JK. Evidence for statin pleiotropy in humans: differential effects of statins and ezetimibe on rho-associated coiled-coil containing protein kinase activity, endothelial function, and inflammation. Circulation 119: 131-138, 2009.

59. Liu SL, Li YH, Shi GY, Jiang MJ, Chang JH, and Wu HL. The effect of statin on the aortic gene expression profiling. Int J Cardiol 114: 71-77, 2007.

60. Lonn ME, Dennis JM, and Stocker R. Actions of "antioxidants" in the protection against atherosclerosis. Free Radic Biol Med 53: 863-884, 2012.

61. Lu TM, Ding YA, Leu HB, Yin WH, Sheu WH, and Chu KM. Effect of rosuvastatin on plasma levels of asymmetric dimethylarginine in patients with hypercholesterolemia. Am J Cardiol 94: 157-161, 2004.

62. Makabe S, Takahashi Y, Watanabe H, Murakami M, Ohba $\mathrm{T}$, and Ito $\mathrm{H}$. Fluvastatin protects vascular smooth muscle cells against oxidative stress through the Nrf2-dependent antioxidant pathway. Atherosclerosis 213: 377-384, 2010.

63. Margaritis M, Channon KM, and Antoniades C. Statins and vein graft failure in coronary bypass surgery. Curr Opin Pharmacol 12: 172-180, 2012.

64. Maron BA and Michel T. Subcellular localization of oxidants and redox modulation of endothelial nitric oxide synthase. Circ J 76: 2497-2512, 2012.

65. Martinez-Gonzalez J, Raposo B, Rodriguez C, and Badimon L. 3-hydroxy-3-methylglutaryl coenzyme a reductase inhibition prevents endothelial NO synthase downregulation by atherogenic levels of native LDLs: balance between transcriptional and posttranscriptional regulation. Arterioscler Thromb Vasc Biol 21: 804-809, 2001.

66. Mihaylova B, Emberson J, Blackwell L, Keech A, Simes J, Barnes EH, Voysey M, Gray A, Collins R, and Baigent C. The effects of lowering LDL cholesterol with statin therapy in people at low risk of vascular disease: meta-analysis of individual data from 27 randomised trials. Lancet 380: 581590, 2012.

67. Mills EJ, O'Regan C, Eyawo O, Wu P, Mills F, Berwanger $\mathrm{O}$, and Briel M. Intensive statin therapy compared with 
moderate dosing for prevention of cardiovascular events: a meta-analysis of $>40,000$ patients. Eur Heart J 32: 14091415, 2011.

68. Mitani H, Egashira K, Ohashi N, Yoshikawa M, Niwa S, Nonomura K, Nakashima A, and Kimura M. Preservation of endothelial function by the HMG-CoA reductase inhibitor fluvastatin through its lipid-lowering independent antioxidant properties in atherosclerotic rabbits. Pharmacology 68: 121-130, 2003.

69. Morawietz H, Erbs S, Holtz J, Schubert A, Krekler M, Goettsch W, Kuss O, Adams V, Lenk K, Mohr FW, Schuler G, and Hambrecht R. Endothelial protection, AT1 blockade and cholesterol-dependent oxidative stress: the EPAS trial. Circulation 114: I296-I301, 2006.

70. Morgan MJ and Liu ZG. Crosstalk of reactive oxygen species and NF-kappaB signaling. Cell Res 21: 103-115, 2011.

71. Morikawa S, Takabe W, Mataki C, Kanke T, Itoh T, Wada Y, Izumi A, Saito Y, Hamakubo T, and Kodama T. The effect of statins on mRNA levels of genes related to inflammation, coagulation, and vascular constriction in HUVEC. Human umbilical vein endothelial cells. J Atheroscler Thromb 9: 178-183, 2002.

72. Morikawa S, Takabe W, Mataki C, Wada Y, Izumi A, Saito Y, Hamakubo T, and Kodama T. Global analysis of RNA expression profile in human vascular cells treated with statins. J Atheroscler Thromb 11: 62-72, 2004.

73. Myung SK, Ju W, Cho B, Oh SW, Park SM, Koo BK, and Park BJ. Efficacy of vitamin and antioxidant supplements in prevention of cardiovascular disease: systematic review and meta-analysis of randomised controlled trials. BMJ 346: f10, 2013.

74. Nanayakkara PW, Kiefte-de Jong JC, ter Wee PM, Stehouwer CD, van Ittersum FJ, Olthof MR, Teerlink T, Twisk JW, van Guldener C, and Smulders YM. Randomized placebo-controlled trial assessing a treatment strategy consisting of pravastatin, vitamin $\mathrm{E}$, and homocysteine lowering on plasma asymmetric dimethylarginine concentration in mild to moderate CKD. Am J Kidney Dis 53: 4150, 2009.

75. Ni Chroinin D, Asplund K, Asberg S, Callaly E, CuadradoGodia E, Diez-Tejedor E, Di Napoli M, Engelter ST, Furie KL, Giannopoulos S, Gotto AM Jr., Hannon N, Jonsson F, Kapral MK, Marti-Fabregas J, Martinez-Sanchez P, Milionis HJ, Montaner J, Muscari A, Pikija S, Probstfield J, Rost NS, Thrift AG, Vemmos K, and Kelly PJ. Statin therapy and outcome after ischemic stroke: systematic review and metaanalysis of observational studies and randomized trials. Stroke 44: 448-456, 2013.

76. Oguz A and Uzunlulu M. Short term fluvastatin treatment lowers serum asymmetric dimethylarginine levels in patients with metabolic syndrome. Int Heart J 49: 303-311, 2008.

77. Ortego M, Bustos C, Hernandez-Presa MA, Tunon J, Diaz C, Hernandez G, and Egido J. Atorvastatin reduces NFkappaB activation and chemokine expression in vascular smooth muscle cells and mononuclear cells. Atherosclerosis 147: 253-261, 1999.

78. Ortego M, Gomez-Hernandez A, Vidal C, Sanchez-Galan E, Blanco-Colio LM, Martin-Ventura JL, Tunon J, Diaz C, Hernandez G, and Egido J. HMG-CoA reductase inhibitors reduce I kappa B kinase activity induced by oxidative stress in monocytes and vascular smooth muscle cells. J Cardiovasc Pharmacol 45: 468-475, 2005.
79. Ostad MA, Eggeling S, Tschentscher P, Schwedhelm E, Boger R, Wenzel P, Meinertz T, Munzel T, and Warnholtz A. Flow-mediated dilation in patients with coronary artery disease is enhanced by high dose atorvastatin compared to combined low dose atorvastatin and ezetimibe: results of the CEZAR study. Atherosclerosis 205: 227-232, 2009.

80. Ota H, Eto M, Kano MR, Kahyo T, Setou M, Ogawa S, Iijima K, Akishita M, and Ouchi Y. Induction of endothelial nitric oxide synthase, SIRT1, and catalase by statins inhibits endothelial senescence through the Akt pathway. Arterioscler Thromb Vasc Biol 30: 2205-2211, 2010.

81. Pacher P, Beckman JS, and Liaudet L. Nitric oxide and peroxynitrite in health and disease. Physiol Rev 87: 315-424, 2007.

82. Patrignani P, Panara MR, Tacconelli S, Seta F, Bucciarelli T, Ciabattoni G, Alessandrini P, Mezzetti A, Santini G, Sciulli MG, Cipollone F, Davi G, Gallina P, Bon GB, and Patrono C. Effects of vitamin E supplementation on $\mathrm{F}(2)$-isoprostane and thromboxane biosynthesis in healthy cigarette smokers. Circulation 102: 539-545, 2000.

83. Pei Y, Ma P, Wang X, Zhang W, Zhang X, Zheng P, Yan L, $\mathrm{Xu} Q$, and Dai G. Rosuvastatin attenuates monocrotalineinduced pulmonary hypertension via regulation of Akt/ eNOS signaling and asymmetric dimethylarginine metabolism. Eur J Pharmacol 666: 165-172, 2011.

84. Pelat M, Dessy C, Massion P, Desager JP, Feron O, and Balligand JL. Rosuvastatin decreases caveolin-1 and improves nitric oxide-dependent heart rate and blood pressure variability in apolipoprotein $\mathrm{E}-/-$ mice in vivo. Circulation 107: 2480-2486, 2003.

85. Pereira EC, Bertolami MC, Faludi AA, Salem M, Bersch D, and Abdalla DS. Effects of simvastatin and L-arginine on vasodilation, nitric oxide metabolites and endogenous NOS inhibitors in hypercholesterolemic subjects. Free Radic Res 37: 529-536, 2003.

86. Perez-Guerrero C, Alvarez de Sotomayor M, Jimenez L, Herrera MD, and Marhuenda E. Effects of simvastatin on endothelial function after chronic inhibition of nitric oxide synthase by L-NAME. J Cardiovasc Pharmacol 42: 204-210, 2003.

87. Piechota-Polanczyk A, Goraca A, Demyanets S, Mittlboeck M, Domenig C, Neumayer C, Wojta J, Nanobachvili J, Huk $\mathrm{I}$, and Klinger M. Simvastatin decreases free radicals formation in the human abdominal aortic aneurysm wall via NF-kappaB. Eur J Vasc Endovasc Surg 44: 133-137, 2012.

88. Pignatelli P, Carnevale R, Cangemi R, Loffredo L, Sanguigni V, Stefanutti C, Basili S, and Violi F. Atorvastatin inhibits gp91phox circulating levels in patients with hypercholesterolemia. Arterioscler Thromb Vasc Biol 30: 360367, 2010.

89. Potena L, Frascaroli G, Grigioni F, Lazzarotto T, Magnani G, Tomasi L, Coccolo F, Gabrielli L, Magelli C, Landini MP, and Branzi A. Hydroxymethyl-glutaryl coenzyme a reductase inhibition limits cytomegalovirus infection in human endothelial cells. Circulation 109: 532-536, 2004.

90. Ras RT, Streppel MT, Draijer R, and Zock PL. Flowmediated dilation and cardiovascular risk prediction: a systematic review with meta-analysis. Int J Cardiol, 2012.

91. Ray R, Murdoch CE, Wang M, Santos CX, Zhang M, AlomRuiz S, Anilkumar N, Ouattara A, Cave AC, Walker SJ, Grieve DJ, Charles RL, Eaton P, Brewer AC, and Shah AM. Endothelial Nox4 NADPH oxidase enhances vasodilatation and reduces blood pressure in vivo. Arterioscler Thromb Vasc Biol 31: 1368-1376, 2011. 
92. Ridker PM, Danielson E, Fonseca FA, Genest J, Gotto AM Jr., Kastelein JJ, Koenig W, Libby P, Lorenzatti AJ, MacFadyen JG, Nordestgaard BG, Shepherd J, Willerson JT, and Glynn RJ. Rosuvastatin to prevent vascular events in men and women with elevated C-reactive protein. $N$ Engl J Med 359: 2195-2207, 2008.

93. Rossoni LV, Wareing M, Wenceslau CF, Al-Abri M, Cobb $\mathrm{C}$, and Austin C. Acute simvastatin increases endothelial nitric oxide synthase phosphorylation via AMP-activated protein kinase and reduces contractility of isolated rat mesenteric resistance arteries. Clin Sci (Lond) 121: 449-458, 2011.

94. Rueckschloss U, Galle J, Holtz J, Zerkowski HR, and Morawietz $\mathrm{H}$. Induction of $\mathrm{NAD}(\mathrm{P}) \mathrm{H}$ oxidase by oxidized low-density lipoprotein in human endothelial cells: antioxidative potential of hydroxymethylglutaryl coenzyme A reductase inhibitor therapy. Circulation 104: 1767-1772, 2001.

95. Sacks FM, Pfeffer MA, Moye LA, Rouleau JL, Rutherford JD, Cole TG, Brown L, Warnica JW, Arnold JM, Wun CC, Davis BR, and Braunwald E. The effect of pravastatin on coronary events after myocardial infarction in patients with average cholesterol levels. Cholesterol and Recurrent Events Trial investigators. N Engl J Med 335: 1001-1009, 1996.

96. Scalera F, Borlak J, Beckmann B, Martens-Lobenhoffer J, Thum T, Tager M, and Bode-Boger SM. Endogenous nitric oxide synthesis inhibitor asymmetric dimethyl L-arginine accelerates endothelial cell senescence. Arterioscler Thromb Vasc Biol 24: 1816-1822, 2004.

97. Sezer ED, Sozmen EY, Nart D, and Onat T. Effect of atorvastatin therapy on oxidant-antioxidant status and atherosclerotic plaque formation. Vasc Health Risk Manag 7: 333-343, 2011.

98. Shepherd J, Cobbe SM, Ford I, Isles CG, Lorimer AR, MacFarlane PW, McKillop JH, and Packard CJ. Prevention of coronary heart disease with pravastatin in men with hypercholesterolemia. West of Scotland Coronary Prevention Study Group. N Engl J Med 333: 1301-1307, 1995.

99. Sicard P, Delemasure S, Korandji C, Segueira-Le Grand A, Lauzier B, Guilland JC, Duvillard L, Zeller M, Cottin Y, Vergely C, and Rochette L. Anti-hypertensive effects of Rosuvastatin are associated with decreased inflammation and oxidative stress markers in hypertensive rats. Free Radic Res 42: 226-236, 2008.

100. Skogastierna C, Luksha L, Kublickiene K, Eliasson E, Rane A, and Ekstrom L. Beneficial vasoactive endothelial effects of fluvastatin: focus on prostacyclin and nitric oxide. Heart Vessels 26: 628-636, 2011.

101. Smith SC Jr., Benjamin EJ, Bonow RO, Braun LT, Creager MA, Franklin BA, Gibbons RJ, Grundy SM, Hiratzka LF, Jones DW, Lloyd-Jones DM, Minissian M, Mosca L, Peterson ED, Sacco RL, Spertus J, Stein JH, and Taubert KA. AHA/ACCF Secondary Prevention and Risk Reduction Therapy for Patients with Coronary and other Atherosclerotic Vascular Disease: 2011 update: a guideline from the American Heart Association and American College of Cardiology Foundation. Circulation 124: 2458-2473, 2011.

102. Sorrentino S and Landmesser U. Nonlipid-lowering effects of statins. Curr Treat Options Cardiovasc Med 7: 459-466, 2005.

103. Sun HX, Zeng DY, Li RT, Pang RP, Yang H, Hu YL, Zhang Q, Jiang Y, Huang LY, Tang YB, Yan GJ, and Zhou JG. Essential role of microRNA-155 in regulating endothelium- dependent vasorelaxation by targeting endothelial nitric oxide synthase. Hypertension 60: 1407-1414, 2012.

104. Suwaidi JA, Hamasaki S, Higano ST, Nishimura RA, Holmes DR Jr., and Lerman A. Long-term follow-up of patients with mild coronary artery disease and endothelial dysfunction. Circulation 101: 948-954, 2000.

105. Tawfik HE, El-Remessy AB, Matragoon S, Ma G, Caldwell RB, and Caldwell RW. Simvastatin improves diabetes-induced coronary endothelial dysfunction. J Pharmacol Exp Ther 319: 386-395, 2006.

106. Taylor F, Huffman MD, Macedo AF, Moore TH, Burke M, Davey Smith G, Ward K, and Ebrahim S. Statins for the primary prevention of cardiovascular disease. Cochrane Database Syst Rev 1: CD004816, 2013.

107. Toledano MB and Leonard WJ. Modulation of transcription factor NF-kappa B binding activity by oxidation-reduction in vitro. Proc Natl Acad Sci USA 88: 4328-4332, 1991.

108. Tran CT, Leiper JM, and Vallance P. The DDAH/ADMA/ NOS pathway. Atheroscler Suppl 4: 33-40, 2003.

109. Valkonen VP, Laakso J, Paiva H, Lehtimaki T, Lakka TA, Isomustajarvi M, Ruokonen I, Salonen JT, and Laaksonen R. Asymmetrical dimethylarginine (ADMA) and risk of acute coronary events. Does statin treatment influence plasma ADMA levels? Atheroscler Suppl 4: 1922, 2003.

110. Vecchione C and Brandes RP. Withdrawal of 3-hydroxy3-methylglutaryl coenzyme A reductase inhibitors elicits oxidative stress and induces endothelial dysfunction in mice. Circ Res 91: 173-179, 2002.

111. Virdis A, Colucci R, Versari D, Ghisu N, Fornai M, Antonioli L, Duranti E, Daghini E, Giannarelli C, Blandizzi C, Taddei S, and Del Tacca M. Atorvastatin prevents endothelial dysfunction in mesenteric arteries from spontaneously hypertensive rats: role of cyclooxygenase 2-derived contracting prostanoids. Hypertension 53: 1008-1016, 2009.

112. Vladimirova-Kitova LG and Deneva-Koycheva TI. The effect of simvastatin on asymmetric dimethylarginine and flow-mediated vasodilation after optimizing the LDL level: a randomized, placebo-controlled study. Vascul Pharmacol 56: 122-130, 2012.

113. Wagner AH, Kohler T, Ruckschloss U, Just I, and Hecker M. Improvement of nitric oxide-dependent vasodilatation by HMG-CoA reductase inhibitors through attenuation of endothelial superoxide anion formation. Arterioscler Thromb Vasc Biol 20: 61-69, 2000.

114. Wang HR, Li JJ, Huang CX, and Jiang H. Fluvastatin inhibits the expression of tumor necrosis factor-alpha and activation of nuclear factor-kappaB in human endothelial cells stimulated by C-reactive protein. Clin Chim Acta 353: 53-60, 2005.

115. Wassmann S, Laufs U, Baumer AT, Muller K, Ahlbory K, Linz W, Itter G, Rosen R, Bohm M, and Nickenig G. HMGCoA reductase inhibitors improve endothelial dysfunction in normocholesterolemic hypertension via reduced production of reactive oxygen species. Hypertension 37: 14501457, 2001.

116. Wassmann S, Laufs U, Muller K, Konkol C, Ahlbory K, Baumer AT, Linz W, Bohm M, and Nickenig G. Cellular antioxidant effects of atorvastatin in vitro and in vivo. Arterioscler Thromb Vasc Biol 22: 300-305, 2002.

117. Wei YM, Li X, Xiong J, Abais JM, Xia M, Boini KM, Zhang $\mathrm{Y}$, and Li PL. Attenuation by statins of membrane raftredox signaling in coronary arterial endothelium. J Pharmacol Exp Ther 345: 170-179, 2013. 
118. Wenzel P, Daiber A, Oelze M, Brandt M, Closs E, Xu J, Thum T, Bauersachs J, Ertl G, Zou MH, Forstermann U, and Munzel T. Mechanisms underlying recoupling of eNOS by HMG-CoA reductase inhibition in a rat model of streptozotocin-induced diabetes mellitus. Atherosclerosis 198: 65-76, 2008.

119. Wilson SH, Simari RD, Best PJ, Peterson TE, Lerman LO, Aviram M, Nath KA, Holmes DR Jr., and Lerman A. Simvastatin preserves coronary endothelial function in hypercholesterolemia in the absence of lipid lowering. Arterioscler Thromb Vasc Biol 21: 122-128, 2001.

120. Winchester DE, Wen X, Xie L, and Bavry AA. Evidence of pre-procedural statin therapy a meta-analysis of randomized trials. J Am Coll Cardiol 56: 1099-1109, 2010.

121. Young JM, Strey CH, George PM, Florkowski CM, Sies CW, Frampton CM, and Scott RS. Effect of atorvastatin on plasma levels of asymmetric dimethylarginine in patients with nonischaemic heart failure. Eur J Heart Fail 10: 463-466, 2008.

122. Yu Y, Ricciotti E, Scalia R, Tang SY, Grant G, Yu Z, Landesberg G, Crichton I, Wu W, Pure E, Funk CD, and FitzGerald GA. Vascular COX-2 modulates blood pressure and thrombosis in mice. Sci Transl Med 4: 132ra54, 2012.

123. Zapolska-Downar D, Siennicka A, Kaczmarczyk M, Kolodziej B, and Naruszewicz M. Simvastatin modulates TNFalpha-induced adhesion molecules expression in human endothelial cells. Life Sci 75: 1287-1302, 2004.

124. Zelvyte I, Dominaitiene R, Crisby M, and Janciauskiene S. Modulation of inflammatory mediators and PPARgamma and NFkappaB expression by pravastatin in response to lipoproteins in human monocytes in vitro. Pharmacol Res 45: 147-154, 2002.

125. Zhang L, Gong D, Li S, and Zhou X. Meta-analysis of the effects of statin therapy on endothelial function in patients with diabetes mellitus. Atherosclerosis 223: 78-85, 2012.

126. Zhang LQ, Ma SF, Grigoryev D, Lavoie TL, Xiao HQ, Setterquist R, Li H, Jacobson J, Garcia JG, and Ye SQ. Temporal gene expression analysis of human coronary artery endothelial cells treated with Simvastatin. Gene Expr 14: 229-239, 2008.

127. Zhou G, Ge S, Liu D, Xu G, Zhang R, Yin Q, Zhu W, Chen J, and Liu $X$. Atorvastatin reduces plaque vulnerability in an atherosclerotic rabbit model by altering the 5-lipoxygenase pathway. Cardiology 115: 221-228, 2010.

128. Zhu B, Shen H, Zhou J, Lin F, and Hu Y. Effects of simvastatin on oxidative stress in streptozotocin-induced diabetic rats: a role for glomeruli protection. Nephron Exp Nephrol 101: e1-e8, 2005.

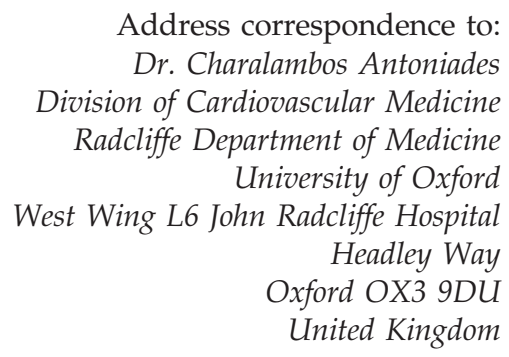

E-mail: charalambos.antoniades@cardiov.ox.ac.uk
Date of first submission to ARS Central, May 16, 2013; date of final revised submission, September 25, 2013; date of acceptance, October 10, 2013.

\section{Abbreviations Used}

$\mathrm{ACS}=$ acute coronary syndrome

$\mathrm{ADMA}=$ asymmetric dimethylarginine

AMPK = adenosine monophosphate activated protein kinase

AP-1 = activator protein-1

$\mathrm{ApoE}=$ apolipoprotein $\mathrm{E}$

$\mathrm{BH}_{4}=$ tetrahydrobiopterin

$\mathrm{CABG}=$ coronary artery bypass graft

$\mathrm{CRP}=\mathrm{C}$-reactive protein

$\mathrm{CVD}=$ cardiovascular disease

$\mathrm{DDAH}=$ dimethylarginine dimethylaminohydrolase

DMAPP $=$ dimethylallyl pyrophosphate $\mathrm{EC}=$ endothelial cell

eNOS $=$ endothelial nitric oxide synthase

$\mathrm{FMD}=$ flow-mediated dilatation

$\mathrm{FPP}=$ farnesylpyrophosphate

GGPP $=$ geranyl-geranyl-pyrophosphate

$\mathrm{GSH}=$ glutathione

$\mathrm{GSH}-\mathrm{Px}=$ glutathione peroxidase

GSSG $=$ glutathione disulfide

$\mathrm{GTPCH}=$ guanosine triphosphate cyclohydrolase

HMG-CoA = 3-hydroxy-3-methylglutaryl coenzyme A

HUVECs = human umbilical vein endothelial cells

ICAM $=$ intercellular adhesion molecule

$\mathrm{I} \kappa \mathrm{B} \alpha=$ inhibitor of $\mathrm{NF}-\kappa \mathrm{B}$ alpha

$\mathrm{IKK}=\mathrm{I} \kappa \mathrm{B}$ kinase

$\mathrm{IL}=$ interleukin

IMA $=$ internal mammary artery

$\mathrm{IPP}=$ isopentenyl pyrophosphate

Keap1 $=$ Kelch like-ECH-associated protein 1

$\mathrm{LDL}=$ low-density lipoprotein

LIPID $=$ Long-Term Intervention with Pravastatin in Ischaemic Disease

LNAME $=N$-nitro-L-arginine methyl ester

$\mathrm{NF}-\kappa \mathrm{B}=$ nuclear factor kappa $\mathrm{B}$

$\mathrm{NO}=$ nitric oxide

$\mathrm{Nrf} 2=$ nuclear factor (erythroid-derived 2)-like 2

$\mathrm{O}_{2}{ }^{-}=$superoxide

$\mathrm{ONOO}^{-}=$peroxynitrite

oxLDL $=$ oxidized LDL

$\mathrm{PGI}_{2}=$ prostacyclin

PI3K = phosphatidylinositide 3-kinase

$\mathrm{PKA}=$ protein kinase $\mathrm{A}$

ROCK $=$ Rho-associated protein kinase

ROS $=$ reactive oxygen species

$\mathrm{SOD}=$ superoxide dismutase

$\mathrm{SVG}=$ saphenous vein graft

$\mathrm{TNF} \alpha=$ tumor necrosis factor alpha

$\mathrm{VCAM}=$ vascular cell adhesion molecule

$\mathrm{VSMC}=$ vascular smooth muscle cell 